\title{
Life cycle assessment of agromining chain highlights role of erosion control and bioenergy
}

Jérémy Rodrigues ${ }^{a}$, Vivian Houzelot ${ }^{a}$, Florent Ferrari ${ }^{a}$, Guillaume Echevarria ${ }^{b}$, Baptiste Laubie ${ }^{a}$, JeanLouis Morel ${ }^{b}$, Marie-Odile Simonnot ${ }^{a}$, Marie-Noëlle Pons ${ }^{a, *}$

a Laboratoire Réactions et Génie des Procédés, Université de Lorraine-CNRS, 1 rue Grandville, BP 20451, 54001 Nancy Cedex, France

${ }^{\mathrm{b}}$ Laboratoire Sols et Environnement, Université de Lorraine-INRA, 2 avenue de la Forêt de Haye, BP 172, 54505 Vandoeuvre-les-Nancy Cedex, France

* Corresponding author. Tel: +33 (0) 383175 277. E-mail: Marie-Noelle.Pons@univ-lorraine.fr

Abstract

Agromining is the recovery of valuable heavy metals from soils with high metal concentrations, using hyperaccumulator plants, to produce value added products. It allows the exploitation of low-grade ores for which conventional mining techniques are too expensive and detrimental to the environment. It is also a means for the restoration of closed mines and heavy metal contaminated soils. On lands of low fertility and high concentration in metals, e.g. serpentine soils in the Balkans, it can provide income sources for the local farmers and improve soil fertility and resistance to erosion.

We presented here the Life Cycle Assessment of an agromining supply chain. This chain included i) the recovery of nickel from serpentine soils in the Balkans with cropped hyperaccumulator Alyssum murale, and ii) the production of ammonium nickel sulfate hexahydrate (ANSH) from the resulting 
ashes using hydrometallurgical processes. Results showed that if not controlled by anti-erosion practices, soil loss at farm scale is responsible for significant impacts, especially on human and environmental health, due to the high heavy metal content of soil particles. However, agromining has a similar impact as normal agricultural practices implemented on the territory. It may be used as cover crop instead of leaving bare soils. Its impact would therefore be beneficial. Heat recovery from biomass combustion avoids significant impact, depending on the energy source it may replace. Proper combustion fume filtration and fly ash recovery reduce risks on human health and maximize metal recovery. Byproducts derived from the process may return to the field to compensate nutrient uptake by crops and improve soil fertility. In conclusion, LCA demonstrated that the whole agromining chain offers the opportunity to promote new agricultural practices and preserve valuable resources. Improvements of the industrial processes are however necessary to increase Ni recovery, purity and added value of final products.

Keywords: Agromining; Bioenergy; Hyperaccumulator; Life Cycle Assessment; Nickel;

\section{Introduction}

Agromining is the recovery and subsequent purification of strategic metals from soils with hyperaccumulating plants (Morel and Mollier, 2013). It is a chain of processes that extract metals from low-grade ores, contaminated soils or wastes, and produce compounds of high added-value (van der Ent et al., 2015), and may help face two trends.

First, because of the increasing need for metals and the depletion of high grade ores, which were historically the first to be used due to their profitability, ore grades have undergone a structural decline (International Council on Mining and Metals (ICMM, 2012)). As a result, for a given amount of extracted metal, the mining industry faces increased waste generation and land degradation, as well as increased challenges in metal extraction at viable economical costs. Second, anthropogenic activities (e.g. mining, industry, urban, waste disposal) may cause accumulation of heavy metals on 
large areas, which cannot be treated with conventional depollution practices (e.g. soil excavation). Unless the polluted areas are under strong urban development pressure, which would allow a quick return on investment, these techniques are prohibitively expensive and hence currently unrealistic.

Both trends illustrate resources increasingly difficult and expensive to exploit/rehabilitate. They therefore call for more extensive and less cost intensive techniques, which would also be more in line with societal demands and expectations regarding sustainable development (Drexhage and Murphy, 2010). Increasing interest has thus been brought on technologies using plants, especially phytoextraction of metals for soil remediation (Chaney, 1983; Baker et al., 1994), from which emerged the concepts of phytomining (Chaney, 1983), and later agromining (Morel and Mollier, 2013; van der Ent et al., 2015).

Metal concentrations are generally higher in hyperaccumulators (HA) than in the soil. The bioaccumulation ratio is superior to unity, and is a key variable, along with biomass yield, to determine the amount of metal harvestable with agromining (Chaney et al., 2007). A high bioaccumulation ratio means it takes less inputs to extract metals from the plants than from the soil itself, as is usually done with conventional mining and depollution processes. With an appropriate choice of $\mathrm{HA}$, agromining could therefore help overcome current technical limitations.

Furthermore, agromining may be compatible with the production of other crops with the phytoextraction of metals, and allow a much quicker post-mining reconversion of the land (van der Ent et al., 2015). It could therefore suitably complete conventional mining and depollution processes, respectively on low-grade ores and heavy metal-contaminated soils.

This paper considers the particular case of nickel ( $\mathrm{Ni})$, which is used in industries such as the production of stainless steel and batteries and in chemistry (surface treatment, paints) (Mudd and Jowitt, 2014). Although its main reserves are located in laterite deposits near the tropics, significant reserves are also available in regions with serpentine soils in Northwestern America, South and Eastern Europe ( Shallari et al., 1998; Prasad, 2005). Agromining of Ni from serpentine soils using the 
HA A. murale was conducted with success in Oregon and Albania (Li et al., 2003; Bani et al., 2007). This Brassicacea is easily found in the Balkan Peninsula, and has an average bioaccumulation ratio of 2.9 for Nickel (Ni) (Shallari et al., 1998). A process was designed to extract $\mathrm{Ni}$ from A. murale, and synthesize salts of Ammonium Nickel Sulfate Hexahydrate (ANSH), that crystallize at low temperature (Barbaroux et al., 2012; Mercier et al., 2012). The process consists of burning the plant and processing the ashes through successive leaching and filtration steps. It has been recently improved to high levels of purity (Zhang, 2014).

Agromining appears a priori as a chain of an environmentally friendly process, as it is based on plant growth and recovery that minimizes the impacts on resources. However, this view strongly related to the green strategies and technologies that arise in various industrial areas must be supported by an objective analysis. Life Cycle Assessment (LCA) is a helpful tool to this end. It is a normed methodology (International Organization for Standardization, 2006) covering the whole life cycle of a commodity, i.e. from the extraction of the resources used to form it to its final disposal. It provides a systemic overview of the life cycle of a product, which is crucial to avoid burden shifting: LCA checks that improvements at one life cycle stage on one potential impact (e.g. climate change caused by energy consumption) are not done at the expense of higher impacts elsewhere (e.g. higher toxic emissions).

This work was conducted to assess the potential impacts of agromining on the environment over its whole life cycle, in order to identify its strengths, weaknesses and improvement opportunities. From the design of an agromining supply chain (Zhang, 2014; Bani et al., 2015), a LCA was run to assess the potential impacts, and identify potential hotspots that may require improvements to minimize environmental impacts when scaling the supply chain up to industrial levels. 


\section{Methods}

\subsection{Scope and functional unit}

LCA was applied on the whole agromining chain, which comprises:

- hyperaccumulator (HA) biomass production, from soil preparation to harvesting, including fertilization, field emissions from machinery (metals) and nutrient/metal flows (e.g. ammonia, phosphate);

- biomass transportation to the processing site;

- biomass grinding and combustion;

- $\quad$ synthesis of Ni-salts from biomass ashes.

The environmental assessment was performed using attributional LCA. The functional unit is $1 \mathrm{~kg}$ of HA plant ashes produced and processed into $353 \mathrm{~g}$ of ANSH (Supplementary Figure F1). All the impacts were allocated to ANSH, which is currently the main product, and chosen as the reference product. By-products are also generated (washing fluids, solid byproducts); they could be reused either within the process or on the field as fertilizers, since they contain elements of agronomic interest (Ca, K, P, Mg). This aspect still needs to be investigated, and is therefore not included in the present assessment.

\subsection{Cropping system}

Alyssum murale naturally grows in the Balkans, on ultramafic soils, i.e. soils originating from rocks with high magnesium/iron oxide content and low silica/potassium content. Those soils exhibit poor nutrient concentrations and high heavy metal concentrations (Supplementary Table S1). When topography allows it, they are occasionally used to grow crops, especially corn or forage, as subsistence agriculture, but with rather low yields, and left fallow afterwards. Agromining could progressively increase soil fertility and reduce soil phytotoxicity to edible crops, helping local farmers to increase their income (van der Ent et al., 2015). 
The low chemical fertility of ultramafic soils strongly limits the yields achievable for agromining $(<3 \mathrm{t}$ of dry weight per ha). Therefore, a cropping system has been designed in order to increase the yields and the available stocks of nutrients (Bani and al. 2007): after soil preparation (ploughing), A. murale seeds are sown by hand in April of year N. They remain in dormant state until September when $A$. murale germinates and the plantlets start to grow. Between April and September, other crops may be allowed to grow on the field. In March of year $\mathrm{N}+1$, the field is weeded by hand. During the following month, it undergoes an initial manual fertilization (phosphorus, potassium, calcium, first dose of nitrogen), a second dose of nitrogen being dispensed in May (Supplementary Table S2). Nitrogen fertilization is split in order to reduce potential nutrient losses. Finally, plants are harvested in June $\mathrm{N}+1$ : they are mown, windrowed, i.e. piled in rows for drying, and pressed by a tractor before being manually loaded on a truck for transportation.

So far, chemical-based fertilization has been implemented (Bani and al. 2007). Those conditions enable to reach a yield of $7 \mathrm{tha}^{-1}$ of $\operatorname{dry}$ matter of $A$. murale, containing $90 \mathrm{~kg}$ of nickel. Work is still in progress on how to substitute chemical-based fertilization by alternative strategies, such as manure spreading, Leguminosae plantation and growth (to fix nitrogen), winter crop in the early stages of $A$. murale development. However, these experiments are not yet mature enough to be fully considered. Only their potential interest against soil erosion will be discussed.

\subsection{Description of the studied processes}

Once the HA biomass is harvested, it is transported by truck (16 t) to its final destination, $50 \mathrm{~km}$ away. Then, production of ANSH follows the steps indicated by Zhang (2014):

1. Biomass is ground with an industrial wood chipper equipped with a $6 \mathrm{~mm}$ grid (11 kW, 85 $\mathrm{kg} / \mathrm{h}$ ) and burnt in a $15 \mathrm{~kW}$ furnace with inner temperatures between 800 and $1000{ }^{\circ} \mathrm{C}$;

2. Ashes are collected and washed twice (mass ratio of water to ash 4:1) with deionized water to remove $\mathrm{K}$; 
3. Washed ashes are leached with $2 M$ sulfuric acid (mass ratio of solution to ash 9:1), filtered and set aside, while the leachate containing the nickel goes to the next step;

4. Leachate is mixed with lime and water, at a ratio of 1:4:2.5 lime $(\mathrm{kg})$, water $(\mathrm{L})$ and leachate (L) respectively. Thus, leachate $\mathrm{pH}$ increases, Fe and some of the excess sulfate precipitate into $\mathrm{FeOOH}$ and gypsum $\left(\mathrm{CaSO}_{4} \cdot 2 \mathrm{H}_{2} \mathrm{O}\right)$, which are filtered out and set aside;

5. Leachate is mixed with sodium fluoride to remove magnesium, by filtration in the form of magnesium fluoride;

6. The purified leachate is heated to evaporate most of its water, reduce leachate volume threefold and bring it closer to $\mathrm{NiSO}_{4}$ solubility limit;

7. Solid ammonium nickel sulfate hexahydrate (ANSH) is crystallized from the leachate, by adding ammonium sulfate at a temperature of $2{ }^{\circ} \mathrm{C}$.

Improved filtration techniques could allow better Ni-recovery yields after liming, only at the expense of increased electricity consumption. Moreover, process effluents from ANSH synthesis could replace demineralized water during ash leaching. This would contribute to increased nickel sulfate concentration in the leachate and bring it closer to ANSH saturation point, with a higher yield. Washing water and gypsum, loaded with key nutrients ( $\mathrm{K}, \mathrm{Ca})$, may be returned to the field for fertilization purpose. Those optimizations have not yet been fully investigated.

\subsection{Specific impacts}

\subsubsection{Field occupation and emission impacts}

Agromining is considered to transform arable fallow land into arable land, which is then occupied as long as agromining activities occur, i.e. as long as $\mathrm{Ni}$ soil concentrations allow high extraction rates. Assuming a nickel concentration of $3.15 \mathrm{~g} \mathrm{Ni}\left(\mathrm{kg}_{\mathrm{dry}} \text { soil }\right)^{-1}$ (Bani et al. 2015) and a constant extraction yield of $90 \mathrm{~kg} \mathrm{Ni}$ per ha and per harvest of $A$. murale, it would take 140 harvests to extract all the nickel present in the first $30 \mathrm{~cm}$ of topsoil, without considering erosion. 
From sowing to harvest, a cropping cycle takes 14 months (from April year $N$ to June year $N+1$ ). However, when dealing with land use impacts, it is considered that the cropping cycle of a plant starts at the harvest of its predecessor, and ends when the plant leaves the field (after harvest or drying on site) (Nemecek et al., 2014). Table 1 illustrates the different possibilities:

A. After A. murale is harvested, the field is left fallow before another cycle begins. Then, one cropping cycle lasts $2 \mathrm{yr}$.

B. A. murale is sown and harvested every year, while the vegetation already in place is still growing. Seeded plants are in dormant state from sowing until after their predecessors have been harvested; therefore no competition for resources is expected between the two generations. Soil preparation is done before the very first sowing of $A$. murale and repeated every 3 to $5 \mathrm{yr}$. In this case, one cropping cycle lasts $1 \mathrm{yr}$.

C. A. murale is part of a diverse cropping system. Here, one cropping cycle lasts $2 \mathrm{yr}$, but part of it is allocated to the other species grown on the field (forage, legumes, corn), according to the recommendations of Nemecek et al. (2014). If those species are harvested at the beginning of $A$. murale growth, only 10 months of the cropping cycle are allocated to $A$. murale in terms of impacts. This cropping system is possible as long as intercrops and $A$. murale do not compete and as harvesting one crop does not jeopardize the other. In practical terms, intercrop harvest should occur before the end of $A$. murale dormant state, and vice versa.

Please insert Table 1

The impacts of $A$. murale were assessed using the methodology described by Nemecek et al. (2014) (Supplementary Tables S3, 4, 5 and 6). Cover was assumed similar to rapeseed (Brassica napus) cover, since A. murale and rape are both Brassicaceae. Nitrate emissions were quantified with the SALCA-NO3 model (Richner et al., 2014). Element losses through erosion are calculated for heavy 
metals and phosphate, using the Revised Universal Soil Loss Equation (Wischmeier and Smith, 1978; Renard et al., 1997; Faist Emmenegger et al., 2009; Panagos et al., 2015a, 2015b; ). Without specific actions against erosion, the potential soil loss is $27 \mathrm{tha}^{-1} \mathrm{yr}^{-1}$, i.e. roughly $2 \mathrm{~mm} \mathrm{yr}^{-1}$. Actually, loss may be lower, because of the occasional presence of low stone walls bordering the fields.

Finally, flows of metals out from soils involved by agromining are also considered as a depletion of mineral resource, according to the practice when modelling mining activities. The lower quality of the soil, when compared to conventional ores, was not taken into account, however.

\subsubsection{Emissions from biomass combustion}

In the absence of data, emissions due to $A$. murale burning have been calculated on the basis of the combustible fraction of the dry biomass ( $90 \%$, the remaining $10 \%$ representing the ash content), using available Ecolnvent data on wood pellet combustion in a $9 \mathrm{~kW}$ furnace.

Wood pellets are supposed to be a good proxy for estimating combustion emissions, since harvested biomass is close to woody. However, Ecolnvent datasets mention an ash content of $0.45 \%$ (the combustion of $71 \mathrm{~g}$ wood pellets generating $0.32 \mathrm{~g}$ ashes to produce $1 \mathrm{MJ}$ of heat (low heating value)), much lower than for $A$. murale. Assuming that combustion emissions are proportional to the combustible biomass (90\% of the total biomass), then the combustion of $1 \mathrm{~kg}$ of $A$. murale produces as much energy and emissions as $0.9 \mathrm{~kg}$ of wood pellets. This implies that the combustion in the furnace does not allow a higher mobility of pollutants from the ashes, i.e. that furnace temperature remains below $600{ }^{\circ} \mathrm{C}$ in the case of $\mathrm{Ni}$ (Zhang et al., 2014). The validity of this hypothesis will be discussed. Finally, instead of being disposed of, ashes are used as input to the subsequent processes. After leaching, treated ashes are assumed to be stabilized in cement and landfilled, following the same processes as ashes from de-inking sludge, for which Ecolnvent data is available. This assumption is made because ashes contain most of the uptaken metals $(\mathrm{Zn}, \mathrm{Cr})$, the recovery of which has not been investigated yet. 


\subsection{Life Cycle Impact Assessment with multiple scenarios}

\subsubsection{Computation}

Life cycle assessment was done with SimaPro ${ }^{\circledR} 8.5$ software by PRé Consultants (PRé Consultants, 2015) using the Ecolnvent 3.1 database. The selected characterization method for the LCIA was the one proposed by the International Reference Life Cycle Data System (ILCD), since it uses consensusbased models for the different assessed impact categories, which comprise: climate change, ozone depletion, human toxicity (both cancer and non-cancer effects), particulate matter, ionizing radiation, photochemical ozone formation, acidification, terrestrial and aquatic eutrophication, ecotoxicity, land use, water and mineral resource depletion (EC - JRC - IES, 2011). The main results were also normalized by the annual potential impacts of an average inhabitant of the EU 27 (Benini et al., 2014), in order to identify the most significant impacts, when compared to those of the European economy.

The different studied scenarios must allow us to identify the environmental hotspots of $\mathrm{Ni}$-salts production and which production chain minimizes them. Three main variables were tested: erosion potential, electricity mix and heat recovery from biomass burning.

\subsubsection{Erosion control}

Erosion potential is quite high, assuming that $A$. murale is cropped every year on a given field (case $B$. in Table 1). Being practiced on soils naturally rich in heavy metals, agromining may cause significant impacts. However, these impacts would also occur with corn cultivation. Therefore, we compared the impacts from A. murale cropping to corn cultivation. Practices and biomass production were assumed similar, in order to emphasize the effect of soil loss and metal uptake. The latter was calculated using data on metal content in biomass (Nemecek et al., 2014).

Furthermore, the effects of two different anti-erosion practices on those impacts were compared. The first one was contour farming, which consists of preparing the soil and seeding following the contours of the land, in order to slow down water runoff and erosion, and facilitate infiltration. The 
second one was the use of a winter cover crop between two A. murale croppings (similar to case $\mathrm{C}$. in Table 1). Only the effects on soil retention were considered; increased water retention, soil organic matter and specific impacts associated with those practices were not taken into account. The potential effect of stone walls was also appraised, assuming a density of 3 stone walls per transect of $250 \mathrm{~m}$, and using data from Panagos et al. (2015b). Supplementary Table S7 gathers the changes in input parameters involved by all those scenarios.

Finally, we compared two different interpretations of those results: (1) the impacts caused by $A$. murale cropping in a standalone culture and (2) its impacts if we only consider the change in erosion compared to corn. The latter would highlight the potential role of agromining as an erosion mitigation strategy.

\subsubsection{Potential atmospheric emissions during combustion}

Pollutant emission during HA combustion was assumed similar to the case of ordinary woody biomass. To assess the pertinence of this hypothesis, we tested the potential effects of the atmospheric release of $5 \%$ of the heavy metals contained in the harvested biomass.

\subsubsection{Electricity mix}

The Albanian electricity mix is dominated by hydropower, but, according to the International Energy Agency, the electricity network is unreliable, making it often necessary to use local fuel-powered generators (Bergasse and Kovacevic, 2008). In the absence of more precise data in Ecolnvent datasets on Albanian electricity, electricity mixes were assumed either $100 \%$ hydro-powered (AL-H) or $100 \%$ fuel-powered (AL-F).

In the case of AL-H, the impacts from transmission and conversion of hydroelectricity (high voltage) to consumer (low voltage) were taken into account. We assumed that they follow the same pattern as in Switzerland, from which all electricity network models are derived. In the case of AL-F, we considered the operation of a $<18.64 \mathrm{~kW}$ ( $<25$ horsepower) diesel power generator working at 
steady-state, suited for small scale applications, with an energy yield of $30 \%$. Since it operates close to the end user, the impacts of electricity network were neglected.

Furthermore, we wanted to determine if it was environmentally beneficial to transport biomass over longer distances to be processed (e.g. $200 \mathrm{~km}$ instead of 50), if it could help use hydroelectricity where the network is more reliable. This scenario is labelled AL-HT.

Another scenario considers an agromining chain in Spain (ES), where ultramafic soils and endemic Nihyperaccumulators can also be found (Cabello-Conejo et al., 2013). To simplify, we assumed that only the electricity mix changes from scenario AL-H to ES, for which data are drawn from Itten et al. (2012).

Finally, we evaluated the potential gain of recovering energy from biomass combustion and using it in substitution to electricity for heating the process. The possibility of heat recovery in substitution of electric heating outside the process was also considered. The latter appears realistic, considering that electric heating of buildings is a current practice in Albania (Bergasse and Kovacevic, 2008). However, the impacts associated with additional equipment (to collect and distribute heat) were not considered.

\section{Results and discussion}

\subsection{Origin of the main impacts}

A first analysis was conducted in the Albanian context using $100 \%$ hydropowered electricity. Biomass is produced every year on a given field (Table 1, case B.), and is transported $50 \mathrm{~km}$ from field to its transformation site. A summary of the corresponding flows is shown in Table 2.

Please insert Tab 2

The repartition of the potential impacts over ANSH life cycle is exhibited in Figure 1 and in supplementary data (Table S8 and Figure F2). Direct and indirect agricultural emissions generate most of the potential impacts. The most relevant flows and processes susceptible of causing 
environmental damage are pointed out in Supplementary Table S9. Its core conclusions are summed up as follows.

Please insert Fig 1

Flows of substances that are toxic to human or the environment represent the most significant impact, in comparison to average European economy.

Freshwater ecotoxicity and human carcinogenic toxicity are strongly affected by soil erosion induced by non-conservative agriculture, which causes a release of $\mathrm{Cr}$ and $\mathrm{Ni}$ from soil to water, where they have stronger availability and negative impacts (Supplementary Figures 3 and 4). This release is higher than on an average agricultural soil, simply because of the particularly high $\mathrm{Ni}$ and $\mathrm{Cr}$ concentrations in ultramafic soils.

However, $\mathrm{Zn}$-uptake by plants has a strong beneficial effect on non-carcinogenic toxicity, which by far compensates the toxicity induced by other flows (Supplementary Figure 5). Zinc removal from soil through erosion contributes to a lesser extent to this beneficial impact. Thus, the impacts of agromining on total human toxicity (cancer and non-cancer effects) would turn out to be beneficial.

Nevertheless, this beneficial effect of $\mathrm{Zn}$ uptake has much to do with the current use of the soils used to crop A. murale. Since they occasionally support subsistence agriculture, they were considered as agricultural soils, for which heavy metal characterization factors are significantly higher than those of unspecified soils, such as defined in Ecolnvent nomenclature. The underlying cause is that agricultural soils are used to feed humans or livestock. Therefore, they present a higher risk to allow heavy metal ingestion by humans via metal transfer to the food chain. If the studied field was considered non-agricultural, the benefit granted by $\mathrm{Zn}$ uptake would collapse, leaving only the detrimental effects of $\mathrm{Zn}$ emissions to water through soil erosion.

Soil erosion and nutrient loss also have detrimental effects on eutrophication; they represent more than $60 \%$ of the eutrophication potential, the rest being shared in roughly equal proportions between (1) fertilizer fabrication and (2) other processes. 
Land use impacts need to be considered with care. They appear as dominated by the occupation of an arable land, which would keep the soils at lower contents of organic matter than what would occur without agromining. This is questionable, since the implemented cropping practices greatly improve local plant productivity. It could therefore increase soil organic matter, which would result in a beneficial impact. However, soil loss through erosion, among other negative consequences, also involves a loss of $73 \mathrm{~kg} \mathrm{Cha}^{-1} \mathrm{yr}^{-1}$, which would significantly increase land use impacts. The clear balance between those two contradictory factors requires a more thorough assessment of carbon fixation in soil.

The climate change indicator is mainly affected by the fabrication of fertilizers and by the disposal of waste ashes, using cement. Depletion of mineral resources is mainly due to nickel extraction and the depletion of indium resources due to the use of sulfuric acid, some part of which is a by-product of lead production.

\subsection{Effects of improved erosion control and cropping practices}

Soil and nutrient losses are proven to strongly contribute to the overall potential impacts. However, those impacts would be significantly higher with corn cultivation, already performed on those soils (Figure 2). Concerning human toxicity, no consideration was taken here on the transfers of metals from corn to human or livestock. This would undoubtedly further increase the benefit of $A$. murale against corn cultivation.

\section{Please insert Fig 2}

A. murale cultivation impacts more severely on mineral resources, but this trait is common to all mining activities. More surprisingly, corn cultivation impacts are also quite high, because of higher erosion, but more importantly because of the use of phosphate fertilizers that requires sulfuric acid.

Focusing on agromining, erosion mitigation practices have a very significant beneficial effect on several impact categories, reducing them by 12 to $340 \%$ for mineral resource depletion and 
freshwater ecotoxicity respectively. Surprisingly, non-carcinogenic toxicity seems to increase with reduced erosion. This is because less zinc is removed from the field. However, soil erosion only changes heavy metal absolute mass on the field. It is unlikely to significantly change their soil concentration and bioavailability, which are the main variables controlling toxicity, since the studied metals originate from local parent rock. This reduced toxicity should therefore be considered with care.

The marine eutrophication and land use impacts from agromining seem to vary only if co-cropping is implemented, because then these impacts are partially allocated to another crop. It should be noted that the benefits of co-cropping are underestimated because improved nitrate retention, soil loss control and soil organic content were not accounted for yet.

The presence of walls only amplifies the relative benefits of $A$. murale versus corn: impact reductions expected from A. murale cropping and erosion mitigation practices come to exceed $100 \%$, as exemplified by freshwater ecotoxicity and carcinogenic toxicity.

If we only consider the change in erosion involved by agromining compared to corn cultivation, its overall toxicity impacts become clearly beneficial (Supplementary Figure F6). This implies that agromining could help reduce erosion, as an alternative to leaving bare soils after use. The stronger the initial erosion potential, the stronger the benefit generated by agromining

\subsection{Additive emissions from combustion}

The simulated emission of $5 \%$ of the heavy metals contained in biomass during combustion only increased freshwater ecotoxicity and non-carcinogenic human toxicity, which are almost entirely affected by $\mathrm{Ni}$ and $\mathrm{Zn}$, respectively (Supplementary Table $\mathrm{S10}$ ). The emission of $5 \%$ of uptaken $\mathrm{Ni}$ increases by $10 \%$ life cycle ecotoxicity, while that of $\mathrm{Zn}$ reduces by $1.5 \%$ the benefits from metal uptake on non-carcinogenic human toxicity.

In practice, given similar combustion temperatures in the furnace $\left(800-1000{ }^{\circ} \mathrm{C}\right)$ for heavy metal contaminated biomass, the fraction of vaporized metals can either remain below $5 \%$ or rank up to 30 
to $55 \%(\mathrm{~Pb}, \mathrm{Zn}, \mathrm{Cd})$, depending on whether the furnace is equipped with a fabric filter or not (Chalot et al., 2012). Therefore, proper filtration equipment and fly ash recovery may avoid significant environmental risks, as well as the potential loss of valuable elements ( $\mathrm{Ni}, \mathrm{Zn})$.

\subsection{Sensitivity to the electricity mix}

Figure 1 showed that, if the electricity mix is $100 \%$ hydropowered, the impacts of electricity consumption are low in comparison to the rest of the life cycle. This result could be expected, since hydroelectricity has lower impacts than other energy sources. Figure 3 indicates that if another electricity mix was chosen, many life cycle impacts of ANSH would increase dramatically.

\section{Please insert Fig 3}

In the Albanian context, the use of fuel (AL-F) is more detrimental to the environment than hydropower, with the notable exceptions of water and mineral resource depletion, and freshwater ecotoxicity. Indeed, in scenario AL-F, no water is used to run a fuel generator, and no electricity transmission network is required. The deployment of this network requires copper and generates scrap copper, which is assumed, in ecoinvent database, to be mostly landfilled and eventually released to water. More realistically, copper scrap will be recycled due to its market price, thus avoiding these hazardous emissions, and hence questioning the relative advantage of scenario AL-F.

For other impact categories, AL-H presents better performances, so that it is still pertinent to transport biomass $150 \mathrm{~km}$ further (AL-HT), if it allows to use hydroelectricity instead of fuel. In that case, the increased impacts are less than $5 \%$ of those implied by fuel-generated electricity. Finally, Spanish electricity mix (ES) is almost always more detrimental than Albanian electricity, because of the use of coal and, to a lesser extent, gas, that respectively represent 15 and $40 \%$ of Spanish electricity mix. 


\subsection{Advantages of heat recovery}

The production process of ANSH from HA plants requires (1) to burn those plants and (2) to heat up solutions (leaching and concentration steps). Therefore, it would be pertinent to reuse the combustion heat for the following steps, and design the industrial process in a way that allows it. In the current conditions, this would involve significant energy savings, since heat represents approximately $70 \%$ of the process energy needs and only $23 \%$ of the energy released from biomass combustion (Supplementary Figure F1supplementary Figure F4). If we do not take into account the impacts of additive infrastructure (heat exchangers and networks), the reduction of the impacts would be proportional to these savings and to the impacts of the purchased electricity.

In the case of hydropowered electricity $(\mathrm{AL}-\mathrm{H}, \mathrm{AL}-\mathrm{HT})$, apart from water resource depletion and ecotoxicity, no impact category would change significantly (Table 3). It would then probably not be worthy to invest significant effort on infrastructure for heat recovery. As for scenarios based on more polluting energy sources (AL-F, ES), heat recovery could reduce environmental impacts by $20-25 \%$ to $100-130 \%$ on average.

Please insert Table 3

It would then be pertinent to (1) burn the harvested biomass where heat is needed as a substitute for more polluting sources (e.g. fuel), and (2) transport the ashes where they can be processed with clean electricity. The latter supposes however that the local electric network is so unreliable that (polluting) backup technologies are required close to the fields, and can be avoided after transportation.

\subsection{Comparison with conventional nickel products}

It was not possible to compare nickel products synthesized from HA biomass with those from conventional processes for several reasons. First, agromining exploits uses that could not be exploited with conventional mining in the current economic context, and its yearly nickel extraction yields are much lower. It cannot therefore be seen as a competitor with conventional mining. 
Second, little Ecolnvent data are available on major issues such as land transformation and occupation, the efficacy of post-mining restoration and the handling of tailings from sulfidic ores (Althaus and Classen, 2005).

\section{Conclusion}

To our knowledge, this study is the first attempt to assess the sustainability of agromining using LCA. We highlighted the pertinence of using agromining as a complementary cover crop to reduce erosion and HA biomass as bioenergy source, and the moderate impacts of the synthesis of nickel products from $\mathrm{HA}$ ashes.

Soil loss control is a cornerstone to agromining sustainability. It avoids the loss of valuable metals, the release of which could be detrimental to environment and human health. The cropping of HA plants should be coupled with anti-erosion practices, such as contour farming, mulching, and winter cover crops instead of conventional tillage to structure the soils, and a good maintenance of stonewalls to prevent erosion. This would not only result in beneficial impacts on soil, water and human health, but also increase the sustainability of agromining and other local cropping systems.

The heat generated by biomass combustion is a valuable byproduct, the recovery of which could (1) reduce the costs of the agromining supply chain (Chaney et al., 2007) and (2) avoid significant impacts if the local base energy sources for heat are fossil fuels. In the Albanian context, where electricity is close to $100 \%$ based on hydropower, the produced heat does not need to be used internally by the process; it only needs to substitute polluting energies, before the ashes are transported where clean electricity can be used to generate high value added products. Thus, even if the biomass was transported more than $200 \mathrm{~km}$ away from the field, agromining and heat recovery would still be less damaging to the environment.

Some issues were only mentioned in this paper and are still under study: the substitution of synthetic fertilizers by manure spreading and/or legumes cropping, the reuse of process effluents and solid wastes back on the field as fertilizers, improvements on the process to increase Ni-recovery in 
marketable products. Those improvements could significantly reduce the impacts of the cropping system, while maintaining the balance of nutrients on the field and increasing the value added of agromining.

To conclude, it would be pertinent to compare products from agromining with those from conventional mining, in order to assess its pros and cons. However, more data are required to achieve that goal.

\section{ACKNOWLEGDGEMENTS}

The authors are thankful to the financial support of the Agence de Mobilisation Economique (AME) of Lorraine and the European Regional Development Fund, through the LORVER project. 


\section{References}

Althaus, H.-J., Classen, M., 2005. Life Cycle Inventories of Metals and Methodological Aspects of Inventorying Material Resources in ecoinvent (7 pp). Int. J. Life Cycle Assess. 10, 43-49. doi:10.1065/lca2004.11.181.5

Baker, A.J.M., McGrath, S.P., Sidoli, C.M.D., Reeves, R.D., 1994. Environmental biotechnology in waste treatment and recycling The possibility of in situ heavy metal decontamination of polluted soils using crops of metal-accumulating plants. Resour. Conserv. Recycl. 11, 41-49. doi:10.1016/0921-3449(94)90077-9

Bani, A., Echevarria, G., Sulçe, S., Morel, J.-L., 2015. Improving the Agronomy of Alyssum murale for Extensive Phytomining: A Five-Year Field Study. Int. J. Phytoremediation 17, 117-127. doi:10.1080/15226514.2013.862204

Bani, A., Echevarria, G., Sulçe, S., Morel, J.L., Mullai, A., 2007. In-situ phytoextraction of Ni by a native population of Alyssum murale on an ultramafic site (Albania). Plant Soil 293, 79-89. doi:10.1007/s11104-007-9245-1

Barbaroux, R., Plasari, E., Mercier, G., Simonnot, M.O., Morel, J.L., Blais, J.F., 2012. A new process for nickel ammonium disulfate production from ash of the hyperaccumulating plant Alyssum murale. Sci. Total Environ. 423, 111-119. doi:10.1016/j.scitotenv.2012.01.063

Benini, L., Mancini, L., Sala, S., Manfredi, S., Schau, E.M., Pant, R., European Commission, Joint Research Centre, Institute for Environment and Sustainability, 2014. Normalisation method and data for environmental footprints. Publications Office, Luxembourg.

Bergasse, E., Kovacevic, A., 2008. Energy in the Western Balkans: the path to reform and reconstruction. OECD, Paris.

Cabello-Conejo, M.I., Centofanti, T., Kidd, P.S., Prieto-Fernández, á., Chaney, R.L., 2013. Evaluation of plant growth regulators to increase nickel phytoextraction by Alyssum species. Int. J. Phytoremediation 15, 365-375. doi:10.1080/15226514.2012.702806

Chalot, M., Blaudez, D., Rogaume, Y., Provent, A.-S., Pascual, C., 2012. Fate of Trace Elements during the Combustion of Phytoremediation Wood. Environ. Sci. Technol. 46, 13361-13369. doi:10.1021/es3017478

Chaney, R.L., 1983. Plant uptake of inorganic waste constituents, in (Parr, J.F. et al., eds), pp. 50-76, Noyes Data Corp, in: Land Treatment of Hazardous Wastes. Noyes Data Corp, pp. 50-76.

Chaney, R.L., Scott Angle, J., Leigh Broadhurst, C., Peters, C.A., Tappero, R.V., Sparks, D.L., 2007. Improved Understanding of Hyperaccumulation Yields Commercial Phytoextraction and Phytomining Technologies. J. Environ. Qual. 36, 1429. doi:10.2134/jeq2006.0514

Drexhage, J., Murphy, D., 2010. Sustainable Development: From Brundtland to Rio 2012. International Institute for Sustainable Development.

EC - JRC - IES, 2011. International reference life cycle data system (ILCD) handbook: Analysing of existing Environmental Impact Assessment methodologies for use in Life Cycle Assessment. Publications Office, Luxembourg.

Faist Emmenegger, M., Reinhard, J., Zah, R., Ziep, T., Weichbrodt, R., Wohlgemuth, V., Roches, A., Freiermuth Knuchel, R., Gaillard, G., 2009. Sustainability Quick Check for Biofuels intermediate background report 129.

International Council on Mining and Metals (ICMM) (Ed.), 2012. Trends in the Mining and Metals Industry.

International Organization for Standardization (Ed.), 2006. ISO 14040:2006 - Environmental management -- Life cycle assessment -- Principles and Framework. International Organization for Standardization.

Itten, R., Frischknecht, R., Stucki, M., 2012. Life cycle inventories of electricity mixes and grid. treeze Ltd., Uster, Switzerland. 
Li, Y.-M., Chaney, R., Brewer, E., Roseberg, R., Angle, J.S., Baker, A., Reeves, R., Nelkin, J., 2003. Development of a technology for commercial phytoextraction of nickel: economic and technical considerations. Plant Soil 249, 107-115.

Mercier, G., Barbaroux, R., Plasari, E., Blais, J.F., Simonnot, M.-O., Morel, J.L., 2012. Procede de production d'un sel de sulfate double de nickel et d'ammonium a partir de plantes hyperaccumulatrices. 2.731.457.

Morel, J.L., Mollier, P., 2013. Using plants to "micro-mine" metals [WWW Document]. URL http://www.nancy.inra.fr/en/All-the-news/Using-plants-to-micro-mine-metals (accessed 11.9.15).

Mudd, G.M., Jowitt, S.M., 2014. A Detailed Assessment of Global Nickel Resource Trends and Endowments. Econ. Geol. 109, 1813-1841. doi:10.2113/econgeo.109.7.1813

Nemecek, T., Bengoa, X., Lansche, J., Mouron, V., Rossi, V., Humbert, S., 2014. Methodological Guidelines for the Life Cycle Inventory of Agricultural Products. Version 2.0, World Food LCA Database (WFLDB). Quantis and Agroscope, Lausanne and Zurich, Switzerland.

Panagos, P., Borrelli, P., Meusburger, K., Alewell, C., Lugato, E., Montanarella, L., 2015a. Estimating the soil erosion cover-management factor at the European scale. Land Use Policy 48, 38-50. doi:10.1016/j.landusepol.2015.05.021

Panagos, P., Borrelli, P., Meusburger, K., van der Zanden, E.H., Poesen, J., Alewell, C., 2015b. Modelling the effect of support practices (P-factor) on the reduction of soil erosion by water at European scale. Environ. Sci. Policy 51, 23-34. doi:10.1016/j.envsci.2015.03.012

Prasad, M.N.V., 2005. Nickelophilous plants and their significance in phytotechnologies. Braz. J. Plant Physiol. 17, 113-128. doi:10.1590/S1677-04202005000100010

Renard, K.., Foster, G.., Weesies, G.A., McCool, D.K., Yoder, D.C., 1997. Predicting Soil Erosion by Water: A Guide to Conservation Planning with the Revised Universal Soil Loss Equation (RUSLE), Agriculture Handbook. U.S. Department of Agriculture.

Richner, W., Oberholzer, H.R., Knuchel Freiermuth, R., Huguenin, O., Ott, S., Nemecek, T., Walter, U., 2014. Modell zur Beurteilung der Nitratauswaschung in Ökobilanzen - SALCA-NO3. Agroscope Sci. 28.

Shallari, S., Schwartz, C., Hasko, A., Morel, J.L., 1998. Heavy metals in soils and plants of serpentine and industrial sites of Albania. Sci. Total Environ. 209, 133-142. doi:10.1016/S00489697(98)80104-6

SimaPro - World's Leading LCA Software Package | PRé Sustainability [WWW Document], 2015. . Pré Consult. URL https://www.pre-sustainability.com/simapro (accessed 11.13.15).

van der Ent, A., Baker, A.J.-M., Reeves, R.D., Chaney, R.L., Anderson, C.W.-N., Meech, J.A., Erskine, P.D., Simonnot, M.-O., Vaughan, J., Morel, J.-L., Echevarria, G., Fogliani, B., Rongliang, Q., Mulligan, D.R., 2015. Agromining: Farming for Metals in the Future? Environ. Sci. Technol. 49, 4773-4780. doi:10.1021/es506031u

Wischmeier, W.H., Smith, D.D., 1978. Predicting rainfall erosion losses - a guide to conservation planning, Agricultural Handbook. U.S. Department of Agriculture.

Zhang, X., 2014. Hydrometallurgical process for the valorization of nickel contained in hyperaccumulating plants. Université de Lorraine, Nancy.

Zhang, X., Houzelot, V., Bani, A., Morel, J.-L., Echevarria, G., Simonnot, M.-O., 2014. Selection and Combustion of Ni-Hyperaccumulators for the Phytomining Process. Int. J. Phytoremediation 16, 1058-1072. doi:10.1080/15226514.2013.810585 
Table 1: Description of the different cropping cycles possible for A. murale

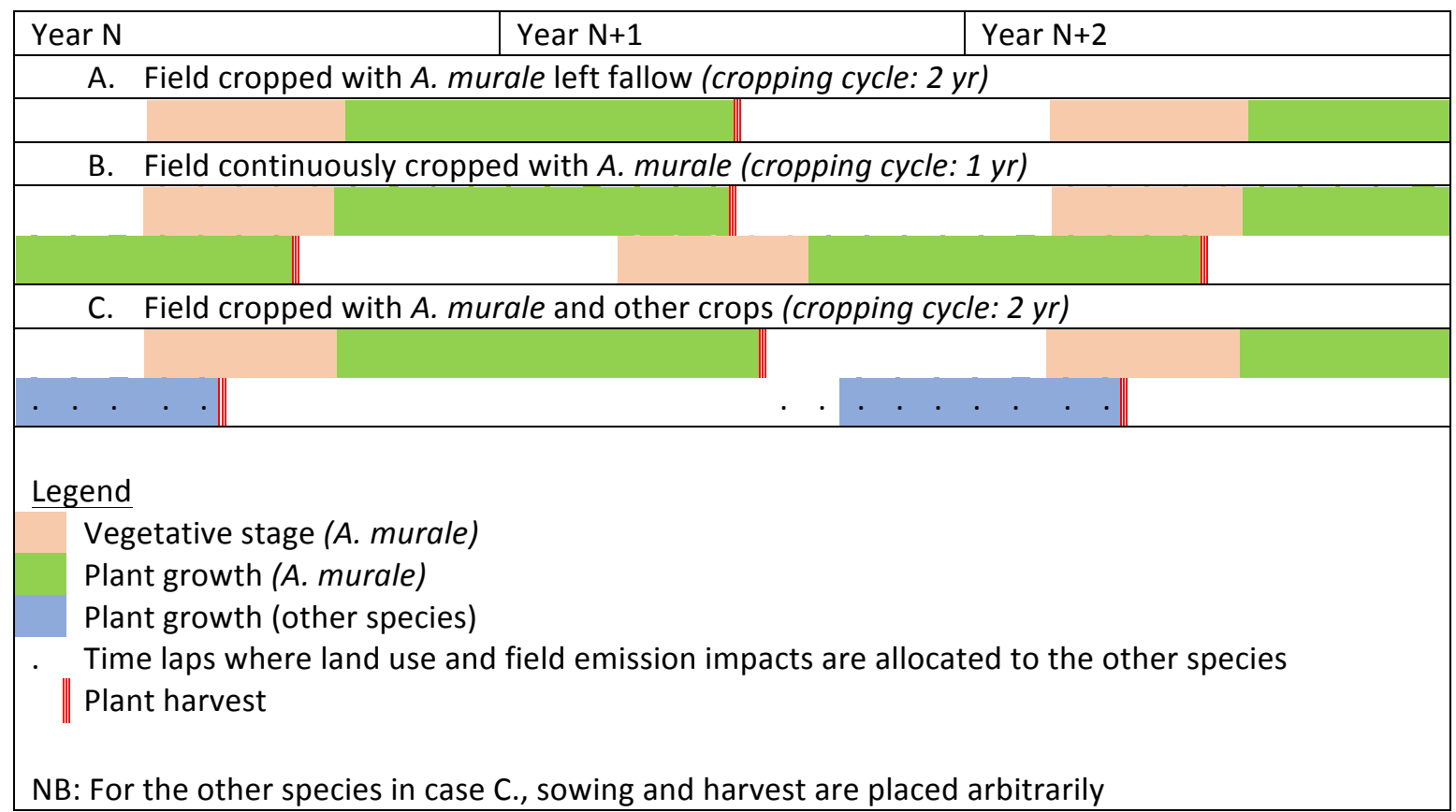


Table 2: Summary of the main inputs and outputs to produce and process $1 \mathrm{~kg}$ of HA ashes

\begin{tabular}{llr}
\hline Flows investigated & Unit & \multicolumn{1}{l}{ Value } \\
\hline Agriculture & & \\
\hline Ammonitrate & $\mathrm{kg}-\mathrm{N}$ & 0.172 \\
Potassium sulfate & $\mathrm{kg}-\mathrm{K} 20$ & 0.172 \\
Phosphate & $\mathrm{kg}-\mathrm{P} 2 \mathrm{O} 5$ & 0.325 \\
Gypsum & $\mathrm{kg}$ & 0.458 \\
Surface ploughed, mown, windrowed & $\mathrm{m}^{2}$ & 14.3 \\
Biomass baling & $\mathrm{kg}$ & 10 \\
Soil loss through erosion* & $\mathrm{kg}$ & 38.9 \\
Transport* & $\mathrm{km}$ & 50 \\
\hline Processes & & \\
\hline Electricity for grinding, agitation, & $\mathrm{MJ}$ & 14.9 \\
filtration & & \\
Heating and cooling & $\mathrm{MJ}$ & 23.6 \\
Heat released by combustion & $\mathrm{MJ}$ & 126 \\
Lime & $\mathrm{kg}$ & 2.3 \\
Sodium fluoride & $\mathrm{kg}$ & 0.1 \\
Ammonium sulfate & $\mathrm{kg}$ & 0.1 \\
Sulfuric acid & $\mathrm{kg}$ & 1.3 \\
Demineralized water & $\mathrm{kg}$ & \\
\hline Products and byproducts & & \\
\hline ANSH & $\mathrm{kg}$ & \\
Nickel-rich solution & $\mathrm{kg}$ & \\
Nickel-rich gypsum & $\mathrm{kg}$ & 4.7 \\
Magnesium fluoride & $\mathrm{kg}$ & 5.4 \\
Waste water & $\mathrm{kg}$ & 0.1 \\
Humid ashes & $\mathrm{kg}$ & 8.0 \\
\hline * Parameters affected by scenario changes, along with electricity \\
mix and heat recovery from combustion & & 1.9 \\
\hline
\end{tabular}




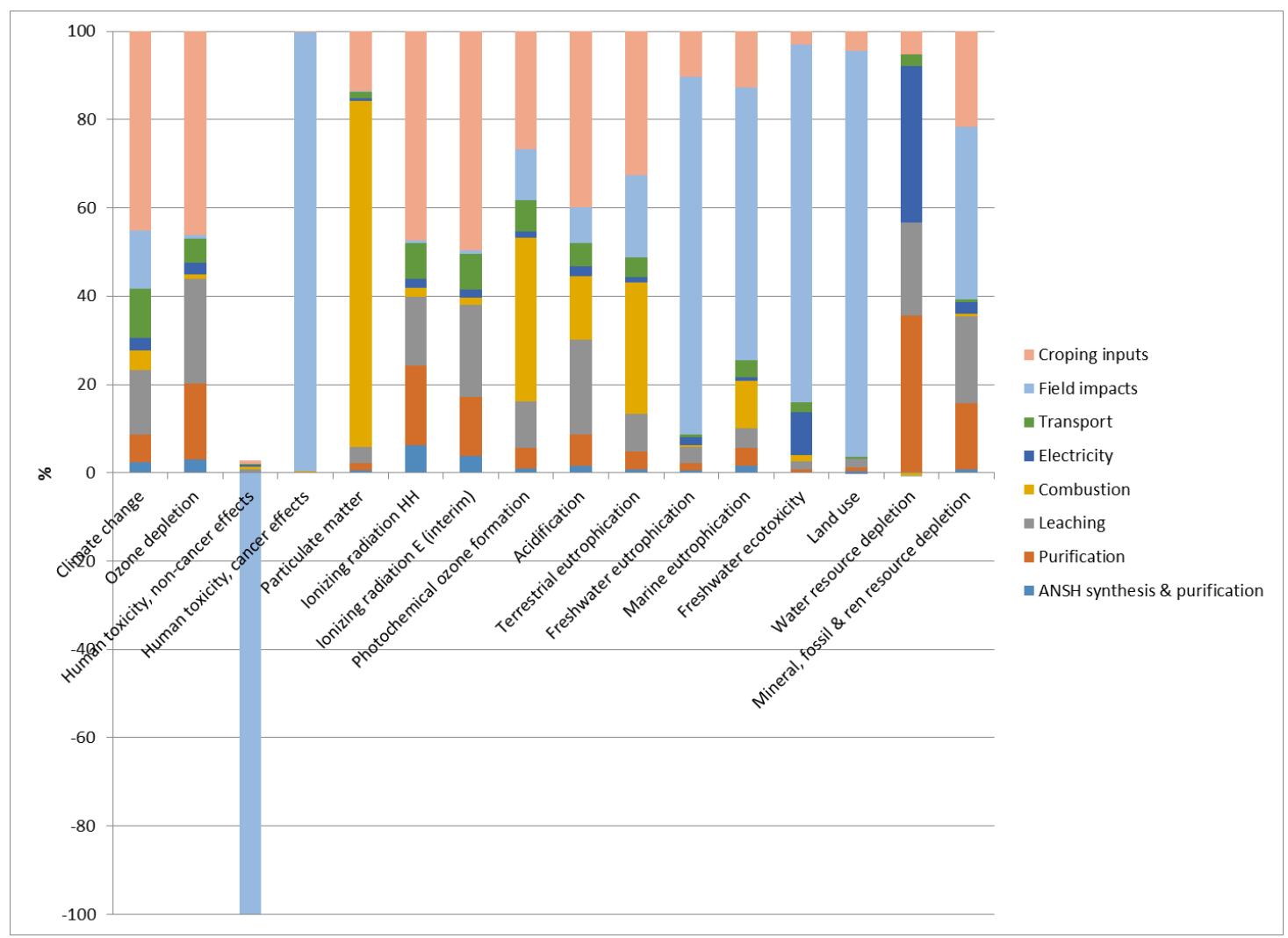

Figure 1: Contribution of the different life cycle stages to the overall life cycle impacts of ANSH produced from A. murale ashes, after biomass has been transported $50 \mathrm{~km}$ 


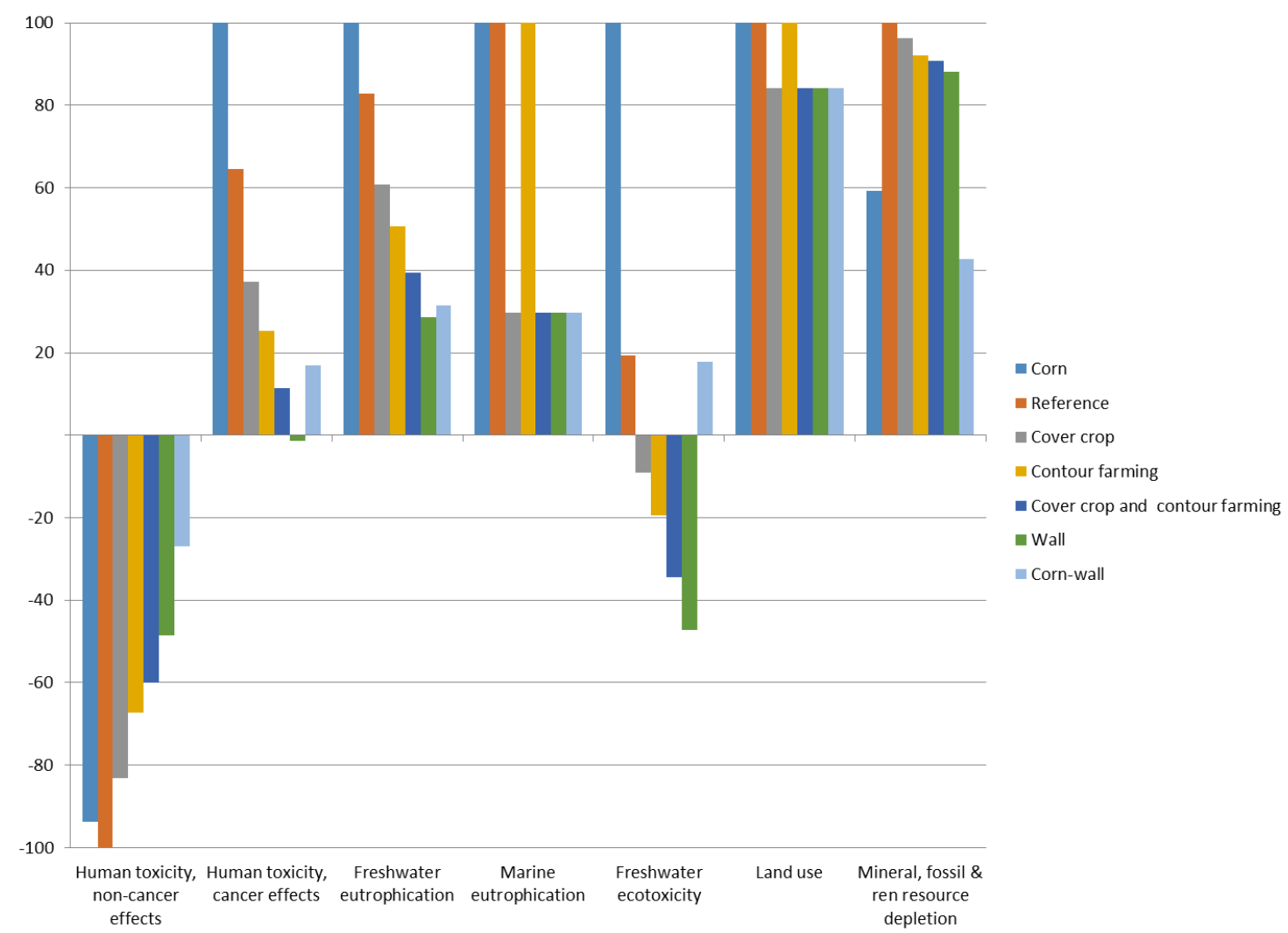

Figure 2: Comparison of different land management and cover practices on the potential impacts of $10 \mathrm{~kg}$ of biomass ( $A$. murale or corn). Focus is made on the impact categories that are affected by changes. 


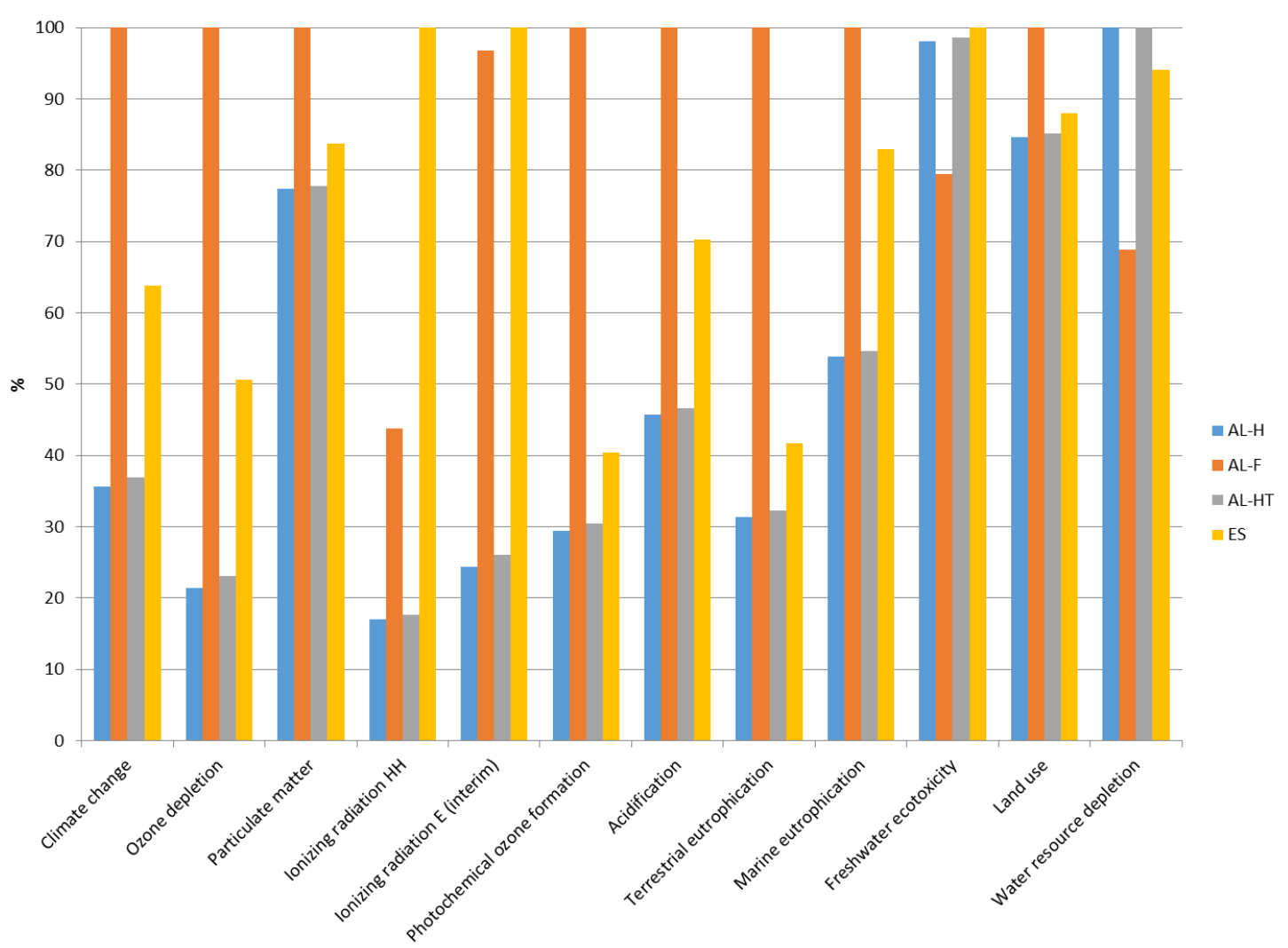

Figure 3: Sensitivity of potential impacts of ANSH to different electricity mixes, focusing on those where significant change occurs 
Table 3: Reduction of the life cycle potential impacts of ANSH production at different levels of heat recovery from biomass combustion, in substitution of electric heating, in \%

\begin{tabular}{lrrrrrrrr}
\hline Scenario and fraction of & AL-H & \multicolumn{3}{c}{ AL-F } & \multicolumn{3}{c}{ AL-HT } & \multicolumn{3}{c}{ ES } \\
\cline { 2 - 9 } combustion heat recovered (\%) & $20 \%$ & $100 \%$ & $20 \%$ & $100 \%$ & $20 \%$ & $100 \%$ & $20 \%$ & $100 \%$ \\
\hline Climate change & 2 & 10 & 45 & 239 & 2 & 9 & 32 & 167 \\
Ozone depletion & 2 & 10 & 55 & 289 & 2 & 8 & 41 & 215 \\
Human toxicity, non-cancer & & & & & & & & \\
effects & 0 & -2 & 0 & -2 & 0 & -1 & -1 & -4 \\
Human toxicity, cancer effects & 0 & 0 & 0 & 2 & 0 & 0 & 0 & 1 \\
Particulate matter & 0 & 2 & 16 & 84 & 0 & 2 & 6 & 29 \\
lonizing radiation HH & 1 & 7 & 43 & 226 & 1 & 6 & 58 & 304 \\
lonizing radiation E (interim) & 1 & 7 & 52 & 274 & 1 & 6 & 53 & 277 \\
Photochemical ozone formation & 1 & 5 & 49 & 259 & 1 & 4 & 19 & 103 \\
Acidification & 2 & 8 & 38 & 202 & 2 & 7 & 25 & 133 \\
Terrestrial eutrophication & 1 & 4 & 48 & 252 & 1 & 4 & 18 & 94 \\
Freshwater eutrophication & 2 & 9 & 4 & 19 & 2 & 8 & 8 & 42 \\
Marine eutrophication & 1 & 3 & 32 & 170 & 1 & 3 & 25 & 130 \\
Freshwater ecotoxicity & 16 & 82 & 3 & 16 & 15 & 73 & 17 & 87 \\
Land use & 0 & 0 & 11 & 56 & 0 & 0 & 3 & 14 \\
Water resource depletion & 25 & 130 & 5 & 24 & 25 & 117 & 22 & 116 \\
Mineral, fossil \& renewable & & & & & & & & \\
resource depletion & 2 & 9 & 2 & 10 & 2 & 8 & 3 & 14 \\
Average reduction (all categories) & 3 & 18 & 25 & 133 & 3 & 16 & 20 & 108 \\
\hline
\end{tabular}




\section{Supplementary materials}

This document gathers the supplementary data, models and results used in Rodrigues et al. (2015)

\section{Supplementary Tables}

\section{Support data on agriculture}

Supplementary Table S2: Elemental composition of the first $30 \mathrm{~cm}$ of topsoil where Alyssum murale is cropped and of produced biomass, compiled from (Bani et al. 2015) and (Barbaroux et al. 2012)

\begin{tabular}{|c|c|c|}
\hline \multirow[t]{2}{*}{ Element } & \multicolumn{2}{|c|}{ Concentration (g/kg dw) } \\
\hline & $\begin{array}{l}\text { Topsoil } \\
\text { (Bani et al. 2015) }\end{array}$ & $\begin{array}{l}\text { Biomass } \\
\text { (Bani et al. 2015) }\end{array}$ \\
\hline Al & 27.0 & \\
\hline $\mathrm{Ca}$ & 3.0 & $11.46 \pm 0.43$ \\
\hline Co & 0.21 & $0.01 \pm 0.00$ \\
\hline $\mathrm{Cr}$ & 1.60 & \\
\hline $\mathrm{Cu}$ & 0.02 & \\
\hline Fe & 10.00 & $0.28 \pm 0.24$ \\
\hline K & 5.0 & \\
\hline Mg & 60 & $6.26 \pm 0.40$ \\
\hline Mn & 2.06 & $0.02 \pm 0.00$ \\
\hline $\mathbf{N}$ & 0.23 & $10.00 \pm 0.60$ \\
\hline $\mathbf{N i}$ & 3.15 & $13.00 \pm 2.15$ \\
\hline $\mathbf{P}$ & 0.17 & $1.80 \pm 0.10$ \\
\hline $\mathrm{Zn}$ & 0.13 & $0.16 \pm 0.02$ \\
\hline
\end{tabular}

Supplementary Table S3: Mains flows of nutrients during one cropping cycle of Alyssum murale (7t dw)

\begin{tabular}{|c|c|c|c|c|c|c|}
\hline Flows (kg/ha) & Dose & $\mathbf{N}$ & $\mathbf{P}$ & $K$ & $S$ & $\mathrm{Ca}$ \\
\hline Exports & & 112 & 6 & 70 & $50-100$ & 90 \\
\hline \multicolumn{7}{|l|}{ Fertilization } \\
\hline $\begin{array}{l}\text { - Ammonium nitrate } \\
(35 \% w \mathrm{~N})\end{array}$ & 340 & 120 & & & & \\
\hline $\begin{array}{l}\text { - Calcium hydrogen } \\
\text { phosphate } \\
\text { (23\%w P-29\%w Ca) }\end{array}$ & 230 & & 100 & & & 125 \\
\hline $\begin{array}{l}\text { - Potassium sulfate } \\
\text { (45\%w K-18\%w S) }\end{array}$ & 220 & & & 100 & 40 & \\
\hline $\begin{array}{l}\cdot \text { Gypsum } \\
\text { (23\%w Ca-19\%w S) }\end{array}$ & $55-320$ & & & & $10-60$ & $15-75$ \\
\hline
\end{tabular}

Comments: Several aspects are notable. First, because of the small areas of farming systems in the Balkans (<3 ha) many interventions are manual. As a consequence, the life cycle of some mechanical operations (e.g. pressing of biomass into bales) may differ from what is described in the available 
data of Ecolnvent (e.g. size of the bales, inputs to bind them). This is however of little importance since baling accounts for less than $1 \%$ of the life cycle impacts for all impact categories.

Second, in the current state, fertilizer application may result in a positive net input of phosphorus, potassium and calcium (Supplementary Table 2). Given the local soil conditions, this actually proves beneficial for the agroecosystem, since those elements are currently poorly available in soils (Bani and al. 2007). 


\section{Support data on field impact assessment}

The calculation rule for some impacts of A. murale (land use, emissions not originating from inputs) has then been derived by Equation (1):

$I_{\text {harvest }}=I_{\text {year }} N_{\text {year }}\left[1-\frac{x_{\text {other }}}{N_{\text {year }}}\right]$

where $I_{\text {harvest }}$ is the impact associated with one harvest of $A$. murale (impact harvest ${ }^{-1}$ ), $I_{\text {year }}$ the impact of $1 \mathrm{yr}$ of the studied cropping cycle (impact $\left.\mathrm{yr}^{-1}\right), N_{\text {year }}$ the number of years of this cropping cycle $(\mathrm{yr})$, and $x_{\text {other }}$ the duration (yr) allocated to another crop (from the harvest of the last $A$. murale crop to that of the studied crop).

Yearly field emissions are estimated according to the recommendations of Nemecek et al. (2014), (Supplementary Table S3).

Supplementary Table S4: Summary of how field emissions are calculated (Nemecek T. et al. 2014)

\begin{tabular}{|c|c|c|}
\hline Element & Compartment (substance or process) & How emission is calculated \\
\hline \multirow[t]{2}{*}{$\mathbf{N}$} & $\begin{array}{l}\text { Air (ammonia, nitrous oxides, dinitrogen } \\
\text { monoxide) }\end{array}$ & Proportional to amount of fertilizer \\
\hline & Groundwater (nitrate) & Calculated with the SALCA-NO3 model \\
\hline $\mathbf{P}$ & $\begin{array}{l}\text { Groundwater and river (leaching) } \\
\text { Surface water (erosion) }\end{array}$ & $\begin{array}{l}\text { Constant } * \text { Correction factor } \\
\text { Soil content } * \text { amount of soil lost } * \\
\text { enrichment and fate factors }\end{array}$ \\
\hline \multirow{2}{*}{$\begin{array}{l}\text { Heavy } \\
\text { metals }\end{array}$} & Groundwater & Constant * Allocation factor \\
\hline & Surface water (erosion) & $\begin{array}{l}\text { Soil content } * \text { amount of soil lost } * \\
\text { enrichment and fate factors }\end{array}$ \\
\hline
\end{tabular}

Both correction and allocation factors are functions of the amount and type of fertilizers applied

For nitrate emissions to water, the SALCA-NO3 model was chosen, because it takes into account the timing of fertilizer application(Richner et al., 2014). A. murale is a Brassicacea considered analog to rape, it is fertilized in April and May of its harvest-year and the fraction of leached fertilizer is $0 \%$ (Richner et al., 2014). Nitrate leaching due to mineralization of soil organic matter is calculated on a monthly basis (Supplementary Table S4). To the calculated potential amount of $\mathrm{N}$-leaching, we need to subtract $\mathrm{N}$-uptake by the plant, i.e. $10 \mathrm{~kg}$ ( $\left.\mathrm{t}_{\text {biomass }}\right)^{-1}$ (Supplementary Table S1Supplementary Table S2). Assuming an annual yield of $7 \mathrm{t} \mathrm{ha}^{-1}, \mathrm{~N}$ uptake is $70 \mathrm{~kg} \mathrm{ha}^{-1} \mathrm{yr}^{-1}$, and therefore, potential $\mathrm{N}$ leaching is: 84.7-70 $=14.7 \mathrm{~kg} \mathrm{ha}^{-1} \mathrm{yr}^{-1}$.

Supplementary Table S5: Expected nitrogen mineralization (kg-N per ha and month, adapted from Richner et al. 2014) and corrected to account for high clay content and low humus content.

\begin{tabular}{|c|c|c|c|c|c|c|c|c|c|c|c|c|c|}
\hline & J & $\mathbf{F}$ & M & A & M & J & J & A & S & $\mathbf{0}$ & $\mathbf{N}$ & D & TOTAL \\
\hline $\begin{array}{l}\text { Without use of a } \\
\text { rotary harrow }\end{array}$ & 0 & 0 & 6 & 9 & 12 & 15 & 17 & 21 & 23 & 12 & 6 & 0 & 121 \\
\hline Emission reduction & & & & & y cor & ent : & $\%>4$ & $\% ; \mathrm{hi}$ & nus $\mathrm{C}$ & tent & $3 \%)$ & & \\
\hline $\begin{array}{l}\text { Case of A. murale } \\
\text { cropping }\end{array}$ & 0 & 0 & 4.2 & 6.3 & 8.4 & $\begin{array}{l}10 . \\
5\end{array}$ & $\begin{array}{l}11 . \\
9\end{array}$ & $\begin{array}{l}14 . \\
7\end{array}$ & $\begin{array}{l}16 . \\
1\end{array}$ & 8.4 & 4.2 & 0 & 84.7 \\
\hline
\end{tabular}


Calculations of nutrient or heavy metal losses were mainly done from two main references (Bani et al. 2015) (Nemecek T. et al., 2014). Details are given in supplementary data (Supplementary Tables S5 and S6).

Supplementary Table S6: Summary of the main emission factors used to quantify field emissions (Nemecek T. et al. 2014)

\begin{tabular}{llll}
\hline Quantified substance & Compartment & Emission factor & Unit \\
\hline Ammonia & Air & 0.03 & $\mathrm{~kg}-\mathrm{N} / \mathrm{kg}-\mathrm{N}$-ammonium nitrate \\
\hline Nitric oxide & Air & 0.012 & $\mathrm{~kg}-\mathrm{N} / \mathrm{kg}-\mathrm{N}$-fertilizer \\
\hline Dinitrogen monoxide & Air & 0.01 & $\mathrm{~kg}-\mathrm{N} / \mathrm{kg}-\mathrm{N}$-fertilizer \\
\hline Phosphate & Groundwater & 0.07 & $\mathrm{~kg}-\mathrm{P} / \mathrm{ha}$ year \\
\hline Phosphate & Run-off water & 0.175 & $\mathrm{~kg}-\mathrm{P} / \mathrm{ha}$ *year \\
\hline
\end{tabular}

Supplementary Table S7: Origin of the data used to calculate field emissions, depending on the element considered, its destination and the data required. When available, local data (Bani et al. 2015) are preferred to generic data (Nemecek T. et al. 2014)

\begin{tabular}{|c|c|c|c|c|c|}
\hline Element & $\begin{array}{l}\text { Deposition or } \\
\text { emission }\end{array}$ & Leaching & Erosion & Inputs & Exportation \\
\hline & Air & Groundwater & Surface water & Soil & Soil \\
\hline & $\begin{array}{l}\text { Annual flow } \\
\text { (mg/ha/year) }\end{array}$ & $\begin{array}{l}\text { Annual flow } \\
\text { (mg/ha/year) }\end{array}$ & $\begin{array}{l}\text { Soil content } \\
\text { (mg/kg soil) }\end{array}$ & $\begin{array}{l}\text { Input content } \\
\text { (mg/kg } \\
\text { nutrient) }\end{array}$ & $\begin{array}{l}\text { Plant content } \\
\text { (mg/kg dry } \\
\text { matter) }\end{array}$ \\
\hline Cd & [1] Tab 21. & [1] Tab 19. & [1] Tab 20. & [1] Tab 23. & [1] Tab 22. \\
\hline $\mathrm{Cu}$ & [1] Tab 21. & [1] Tab 19. & [2] Tab. 1 & [1] Tab 23. & [1] Tab 22. \\
\hline $\mathrm{Cr}$ & [1] Tab 21. & [1] Tab 19. & [2] Tab. 1 & [1] Tab 23. & [1] Tab 22. \\
\hline $\mathrm{Pb}$ & [1] Tab 21. & [1] Tab 19. & [1] Tab 20. & [1] Tab 23. & [1] Tab 22. \\
\hline $\mathrm{Hg}$ & [1] Tab 21. & [1] Tab 19. & [1] Tab 20. & $\mathrm{X}$ & [1] Tab 22. \\
\hline $\mathrm{Ni}$ & [1] Tab 21. & $\mathrm{X}$ & [2] Tab. 1 & [1] Tab 23. & [2] Tab. 3 \\
\hline Co & $\mathrm{X}$ & $\mathrm{X}$ & [2] Tab. 1 & $\mathrm{X}$ & [2] Tab. 3 \\
\hline$M n$ & $\mathrm{x}$ & $\mathrm{x}$ & [2] Tab. 1 & $\mathrm{X}$ & [2] Tab. 3 \\
\hline Zn & [1] Tab 21. & [1] Tab 19. & [2] Tab. 1 & [1] Tab 23. & [2] Tab. 3 \\
\hline \multicolumn{6}{|c|}{$\begin{array}{l}\text { [1] Nemecek et al. } 2014 \\
\text { [2] Bani et al. } 2015\end{array}$} \\
\hline
\end{tabular}

Heavy metal emissions to groundwater are challenging to quantify. Therefore, average values from literature are needed as proxies. In order to quantify the effect of agricultural practices on those emissions, we calculated the contribution of agricultural inputs to the total inputs, which include atmospheric deposition (Nemecek T. et al., 2014).

Element losses through erosion are calculated for heavy metals and phosphate, using the Revised Universal Soil Loss Equation (Renard et al., 1997; Wischmeier and Smith, 1978):

$A_{\text {soil loss }}=R k$ LS C P

where $A_{\text {soil loss }}$ is the potential amount of soil lost through erosion ( $\mathrm{t} \mathrm{ha} \mathrm{yr}^{-1}$ ), R the erosivity (in MJ $\mathrm{m}$ $\mathrm{ha}^{-1} \mathrm{~h}^{-1} \mathrm{yr}^{-1}$ ), describing the erosive force of rainfall, $k$ the erodibility, depending on type of soil $k$ ( $\mathrm{t} h$ $\left.\mathrm{MJ} \mathrm{mm}^{-1}\right), L S$ the field slope and length $(-), C$ and $\mathrm{P}$ are parameters for cropping and anti-erosion practices. $\mathrm{C}$ and $\mathrm{P}$ are described as the product of different subfactors, among which $C_{\text {crop }}$ and $C_{\text {management }}$ characterize land cover and tillage practices (Panagos et al., 2015a, 2015b). 
Parameter values are given by (Faist Emmenegger et al., 2009) and Panagos et al. (2015). Cover was assumed similar to rape cover, since $A$. murale and rape are both Brassicacea, and are submitted to similar cropping practices and have similar growth patterns. Considering a plow parallel to a $5 \%$ slope on a Vertisol, under the local climate and without specific actions against erosion, the potential soil loss is $27 \mathrm{t} \mathrm{ha}^{-1} \mathrm{yr}^{-1}$, i.e. roughly $2 \mathrm{~mm} \mathrm{yr}^{-1}$. Actually, loss may be lower, because of the occasional presence of low stone walls to delineate fields.

Finally, flows of metals out from soils involved by agromining are also considered as a depletion of mineral resource, according to the practice when modelling mining activities. The lower quality of the soil, when compared to conventional ores, was not taken into account, however.

Supplementary Table S8: Influence of different cropping practices on parameters of the Universal Soil Loss Equation (Panagos et al. 2015) and time allocation factors

\begin{tabular}{|c|c|c|c|c|c|c|c|}
\hline & [0] & [1] & [2] & [3] & [4] & [5] & [6] \\
\hline $\mathrm{C}_{\text {crop }}$ & 0.38 & 0.30 & 0.30 & 0.30 & 0.30 & 0.30 & 0.38 \\
\hline$C_{\text {management }}$ & 1 & 1 & 0.8 & 1 & 0.8 & 0.8 & 0.8 \\
\hline P: anti-erosion practices factor & 1 & 1 & 1 & 0.5 & 0.5 & 0.25 & 0.25 \\
\hline $\mathrm{N}$ : cropping cycle length (years) & 1 & 1 & 2 & 1 & 2 & 2 & 2 \\
\hline $\begin{array}{l}\text { x: period with another crop } \\
\text { (months) }\end{array}$ & 0 & 0 & 14 & 0 & 14 & 14 & 14 \\
\hline \multicolumn{8}{|c|}{$\begin{array}{l}\text { [0] Corn: serves as a comparison basis between agromining and current cropping system, } \\
\text { assuming no erosion control practice }\end{array}$} \\
\hline \multicolumn{8}{|c|}{ [1] Reference: A. murale cropping assuming no erosion control practice } \\
\hline \multicolumn{8}{|c|}{ [2] Cover crop: A. murale cropping coupled with winter crop between two A. murale } \\
\hline \multicolumn{8}{|c|}{ [3] Contour farming: A. murale cropping and contour farming } \\
\hline \multicolumn{8}{|c|}{ [4] Cover crop and contour farming: combination of [2] and [3] } \\
\hline \multicolumn{8}{|c|}{ [5] Wall: combination of [4] and stone walls at moderate density on the fields } \\
\hline \multicolumn{8}{|c|}{$\begin{array}{l}\text { [6] Corn-wall: [5] applied to corn, to ultimately compare corn and A. murale if all studied anti- } \\
\text { erosion practices are implemented. }\end{array}$} \\
\hline
\end{tabular}




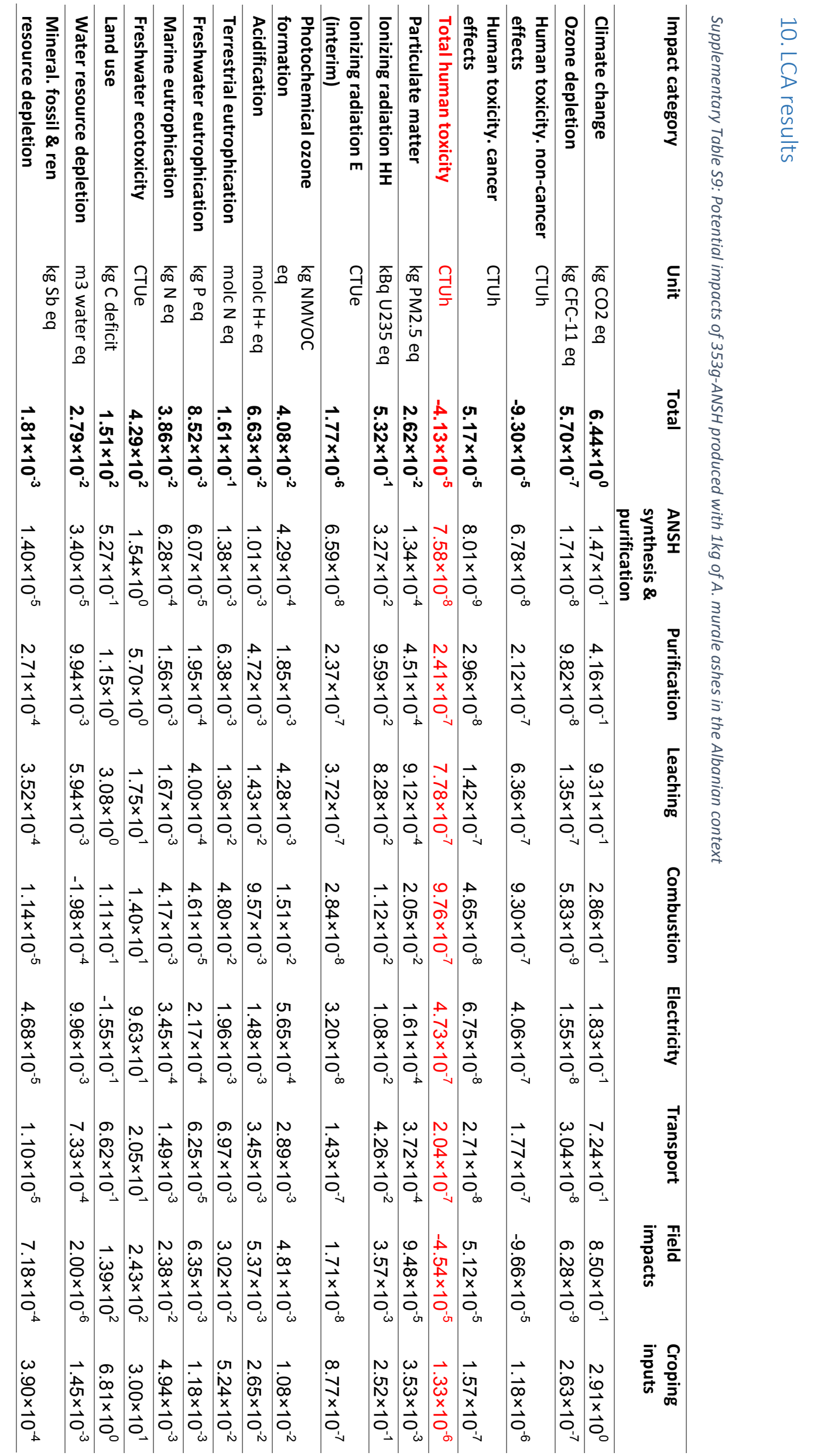


Supplementary Table S10: Main contributors (life cycle steps and substances) to the considered impacts. Substances marked + increase the impact; those marked-decrease the impact

\begin{tabular}{|c|c|c|}
\hline Impact category & Dominant life cycle step & Substance and cause \\
\hline Human toxicity. cancer effects & Field impacts & $\begin{array}{l}\text { + Chromium to water (soil } \\
\text { erosion) } \\
\text { + Nickel to water (soil erosion) } \\
\text { - Chromium loss from the soil } \\
\text { (soil erosion) } \\
\text { - Nickel loss from the soil } \\
\text { (plant uptake) }\end{array}$ \\
\hline $\begin{array}{l}\text { Human toxicity. non-cancer } \\
\text { effects }\end{array}$ & Field impacts & $\begin{array}{l}\text { - Zinc loss from agricultural soil } \\
\text { (plant uptake) }\end{array}$ \\
\hline Freshwater ecotoxicity & Field impacts & $\begin{array}{l}\text { + Chromium to water (soil } \\
\text { erosion) } \\
+ \text { Nickel to water (soil erosion) } \\
\text { - Nickel loss from the soil } \\
\text { (plant uptake) } \\
\text { - Chromium loss from the soil } \\
\text { (plant uptake) }\end{array}$ \\
\hline $\begin{array}{l}\text { Mineral. fossil \& renewable } \\
\text { resource depletion }\end{array}$ & $\begin{array}{l}\text { Mineral uptake by plant } \\
\text { Cropping inputs (fertilization) } \\
\text { Leaching and purification }\end{array}$ & $\begin{array}{l}\text { + Indium extraction from lead } \\
\text { concentrates (to produce part } \\
\text { of the used sulfuric acid) } \\
+ \text { Nickel uptake } \\
\text { + Fluorspar extraction to } \\
\text { produce sodium fluoride }\end{array}$ \\
\hline Particulate matter & Biomass combustion & + PM2.5 to air \\
\hline Freshwater eutrophication & Field impacts & $\begin{array}{l}\text { + Phosphate loss from soil } \\
\text { erosion }\end{array}$ \\
\hline Marine eutrophication & Field impacts & $\begin{array}{l}\text { + Nitrate leaching to } \\
\text { groundwater }\end{array}$ \\
\hline Land use & Field impacts & + Field occupation \\
\hline Acidification & $\begin{array}{l}\text { Cropping inputs } \\
\text { Leaching } \\
\text { Biomass combustion }\end{array}$ & $\begin{array}{l}\text { + Sulfur dioxide (sulfuric acid } \\
\text { production for processes and } \\
\text { P-fertilizer synthesis) } \\
\text { + Nitrogen oxides (biomass } \\
\text { combustion) }\end{array}$ \\
\hline $\begin{array}{l}\text { Photochemical ozone } \\
\text { formation }\end{array}$ & $\begin{array}{l}\text { Biomass combustion } \\
\text { Cropping inputs (fertilizers) }\end{array}$ & $\begin{array}{l}\text { + Nitrogen oxides } \\
\text { + Non-methane organic } \\
\text { volatile compounds }\end{array}$ \\
\hline Terrestrial eutrophication & $\begin{array}{l}\text { Biomass combustion } \\
\text { Cropping inputs (fertilizers) }\end{array}$ & $\begin{array}{l}\text { + Nitrogen oxides } \\
+ \text { Nitric oxide }\end{array}$ \\
\hline Climate change & $\begin{array}{l}\text { Cropping inputs } \\
\text { Leaching (disposal of ashes) } \\
\text { Field emissions }\end{array}$ & $\begin{array}{l}\text { + Carbon dioxide } \\
\text { + Dinitrogen monoxide (field } \\
\text { emissions \& N-fertilizers } \\
\text { synthesis) }\end{array}$ \\
\hline
\end{tabular}




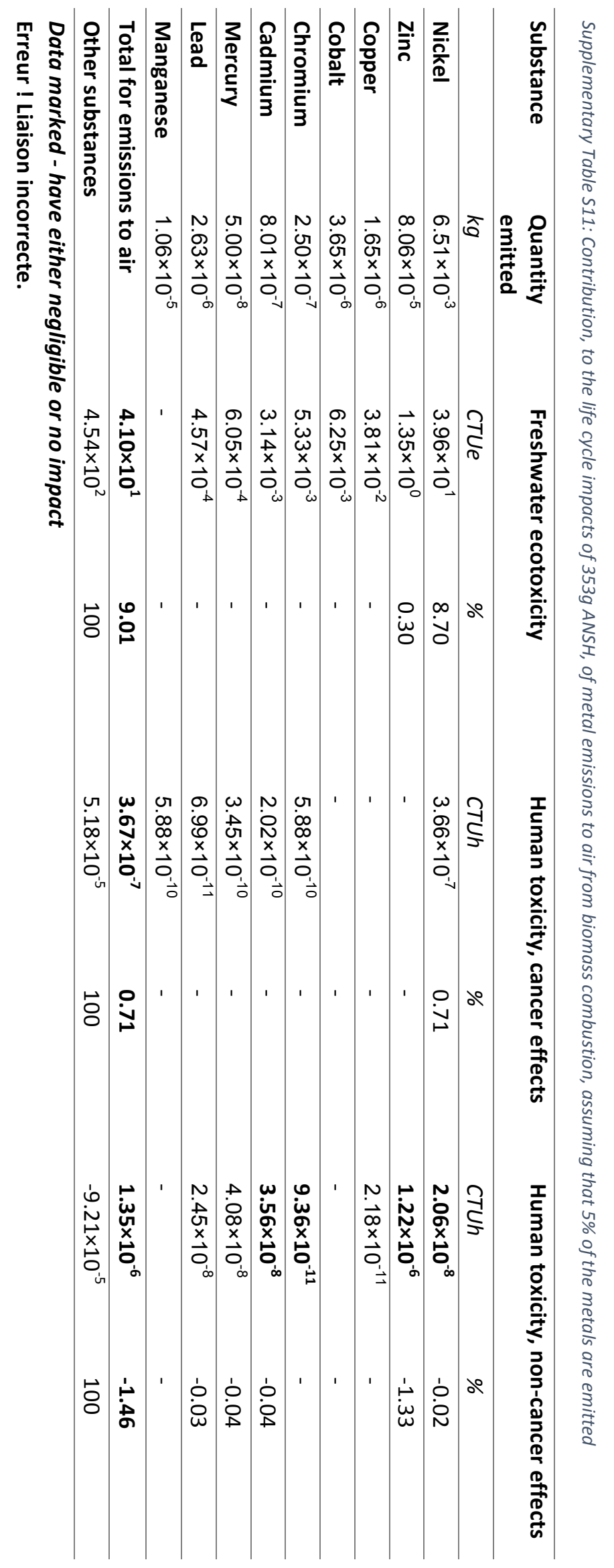




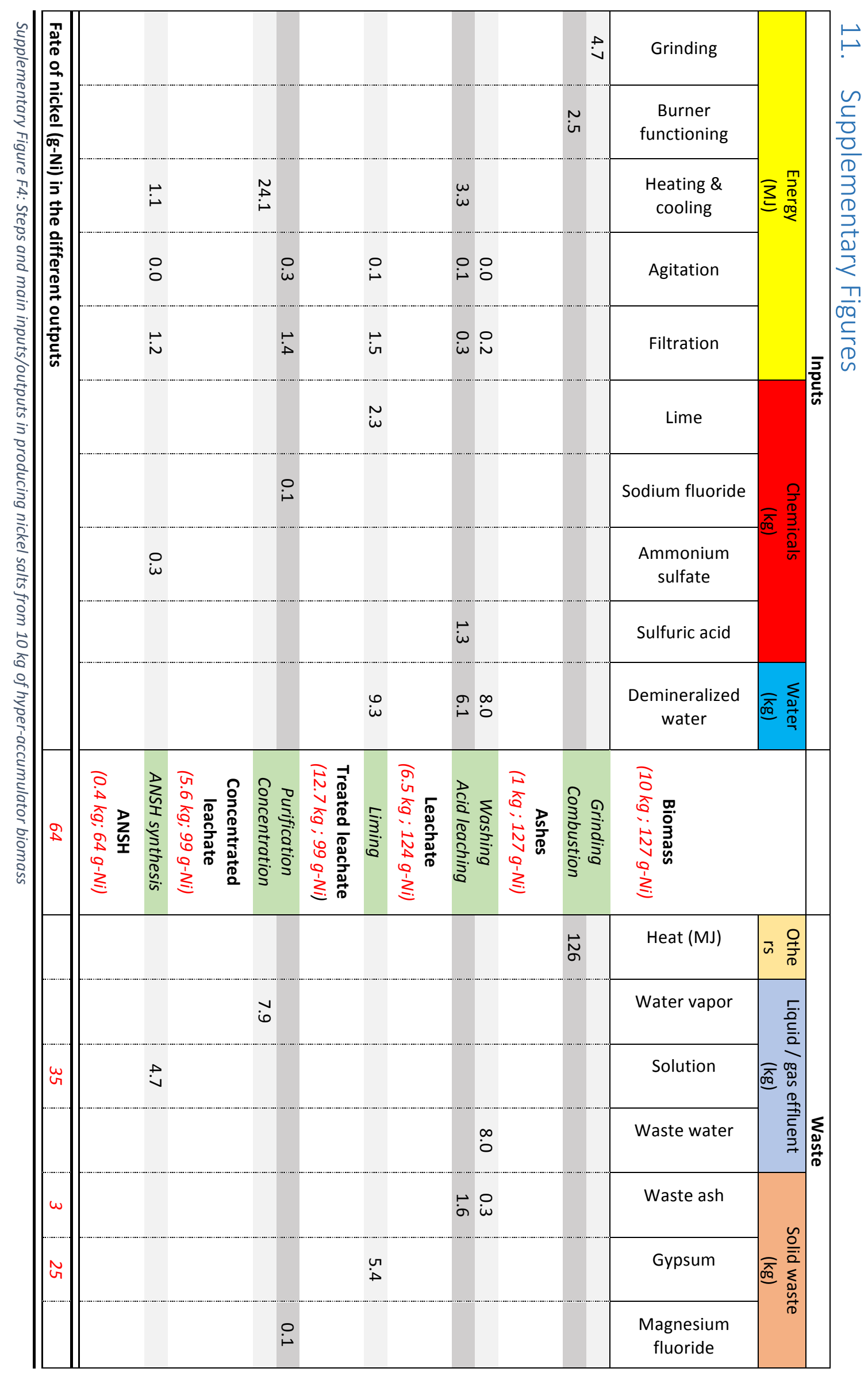




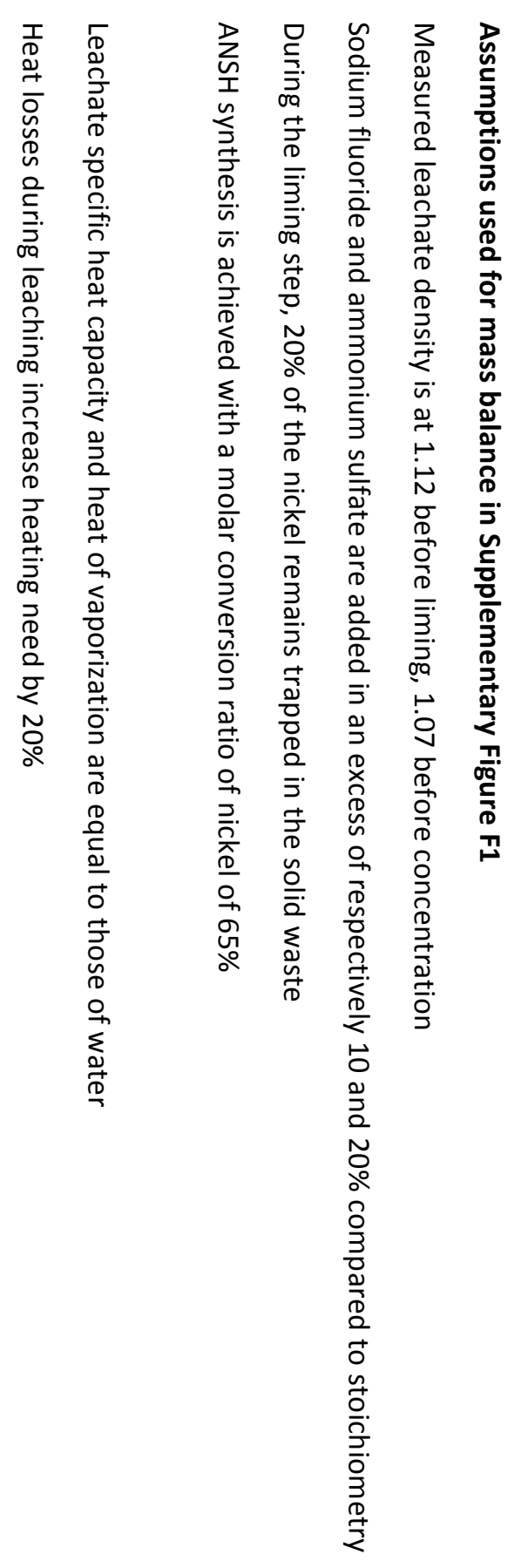



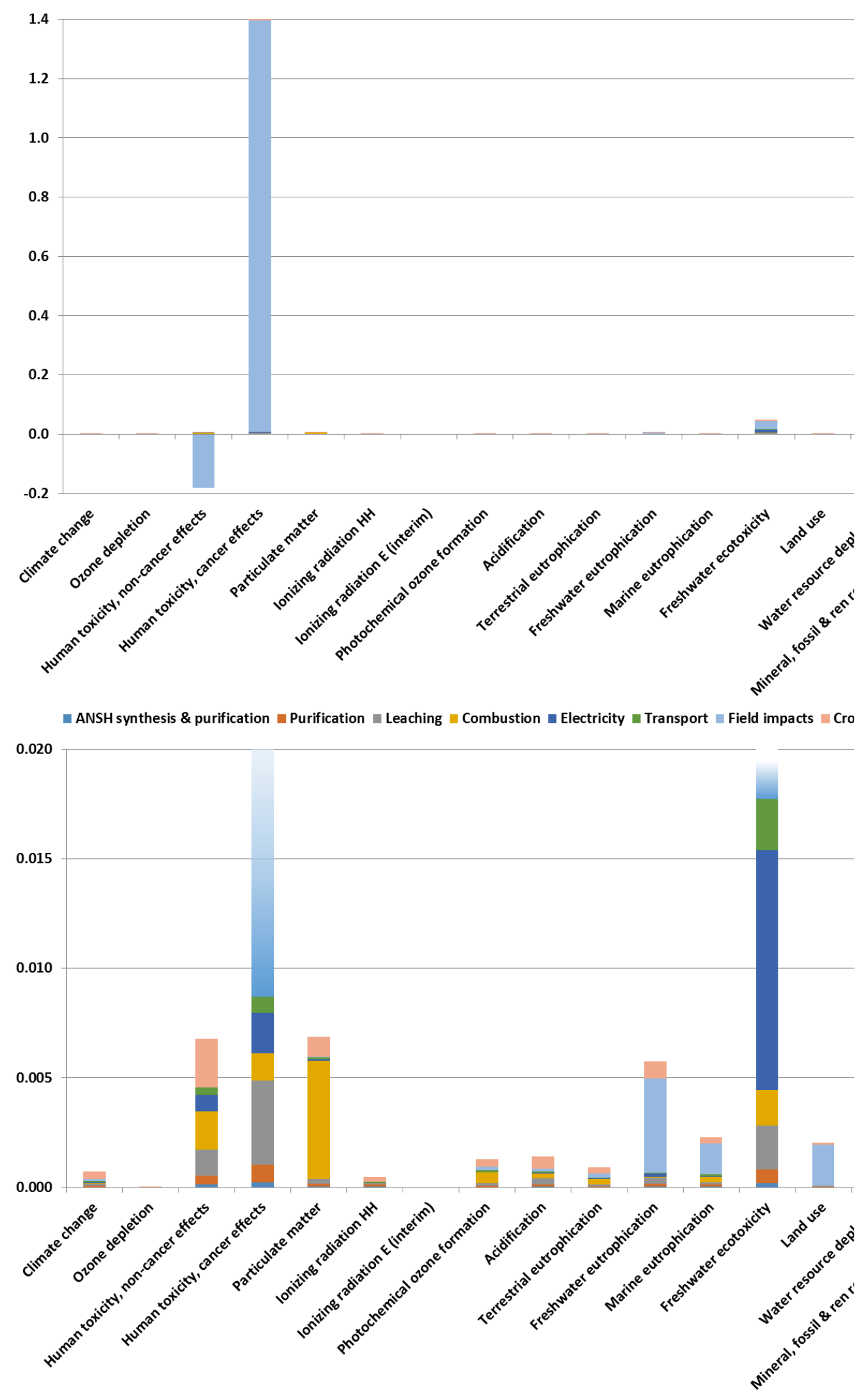

2 Supplementary Figure F5: Life cycle impacts of $353 \mathrm{~g}$ ANSH produced in Albania, normalized by the annual it 3 average inhabitant of EU27. Upper figure shows the global impacts; lower figure zooms on the relatively lo 

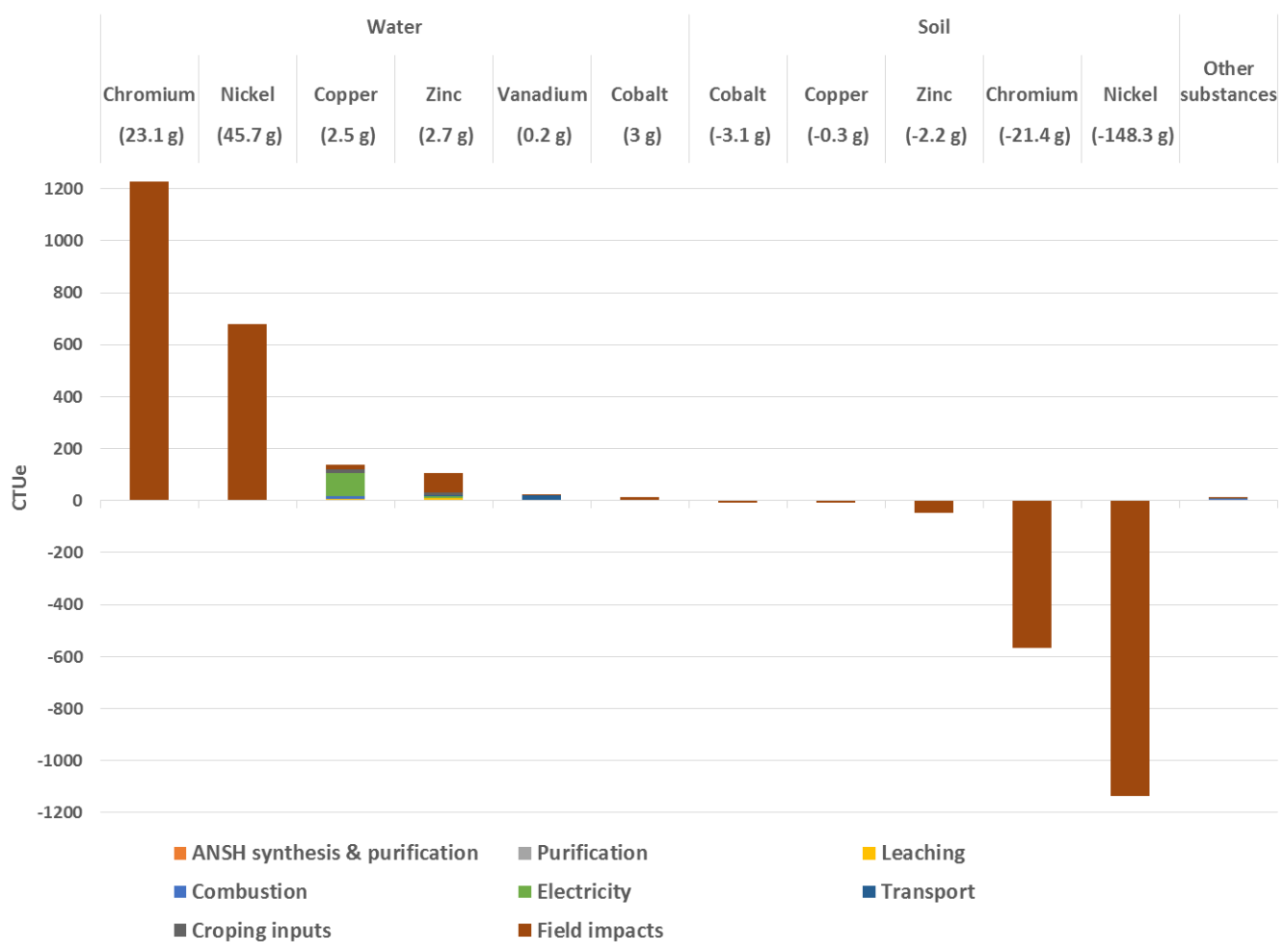

6 Supplementary Figure F6: Contribution of flows of substances to life cycle freshwater ecotoxicity for $353 g$ ANSH, depending 7 of their destination compartment and the emitted quantities 


\begin{tabular}{c|c|c|c|c|c|}
\hline & \multicolumn{3}{|c|}{ Water } & \multicolumn{2}{c}{ Soil } \\
\hline & Chromium & Nickel & Nickel & Chromium & Other substances \\
\hline 14 & $(23,1 \mathrm{~g})$ & $(45,7 \mathrm{~g})$ & $(-148,3 \mathrm{~g})$ & $(-21,4 \mathrm{~g})$ & \\
\hline
\end{tabular}

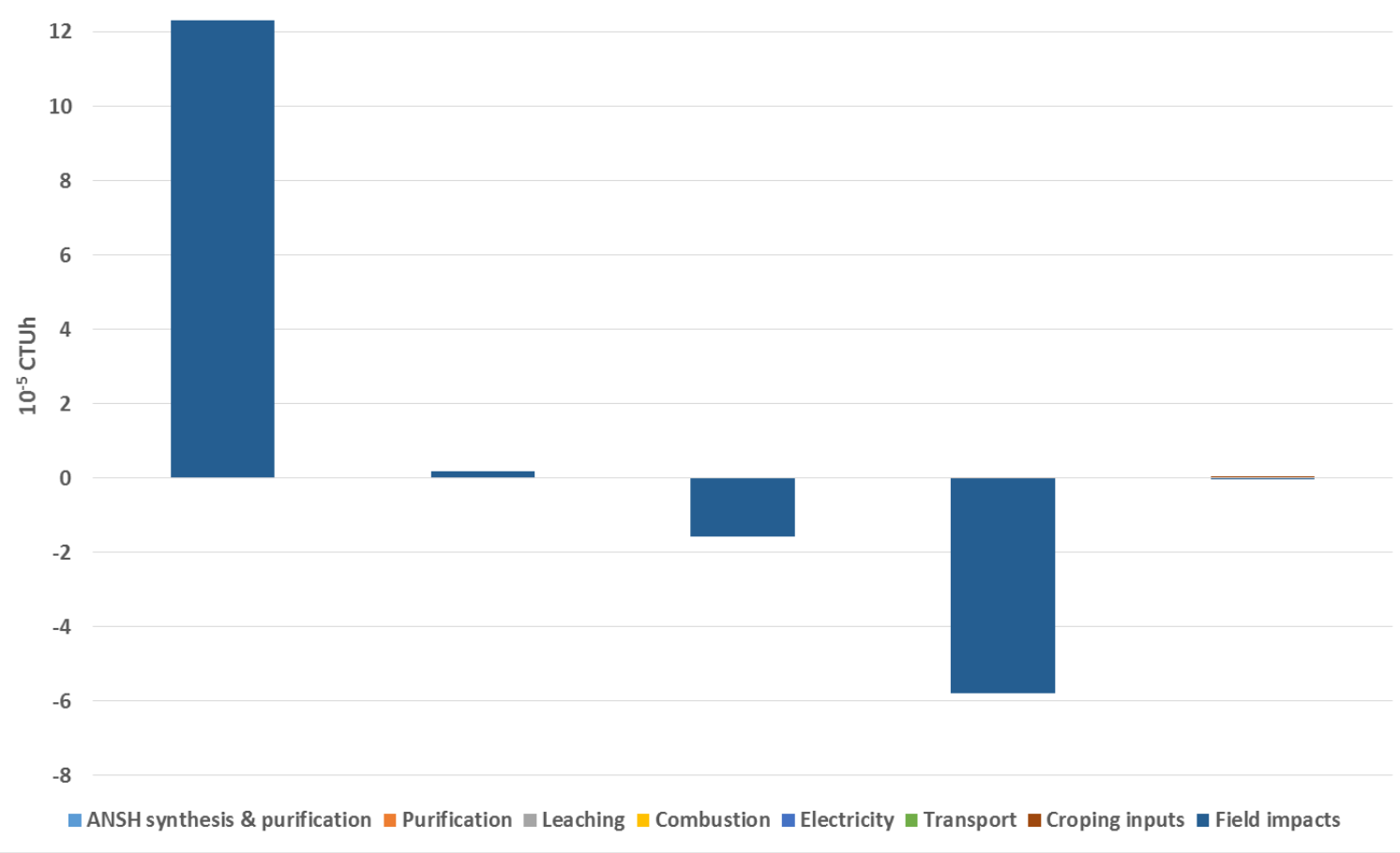
$353 g-A N S H$, depending of their destination compartment and the emitted quantities 


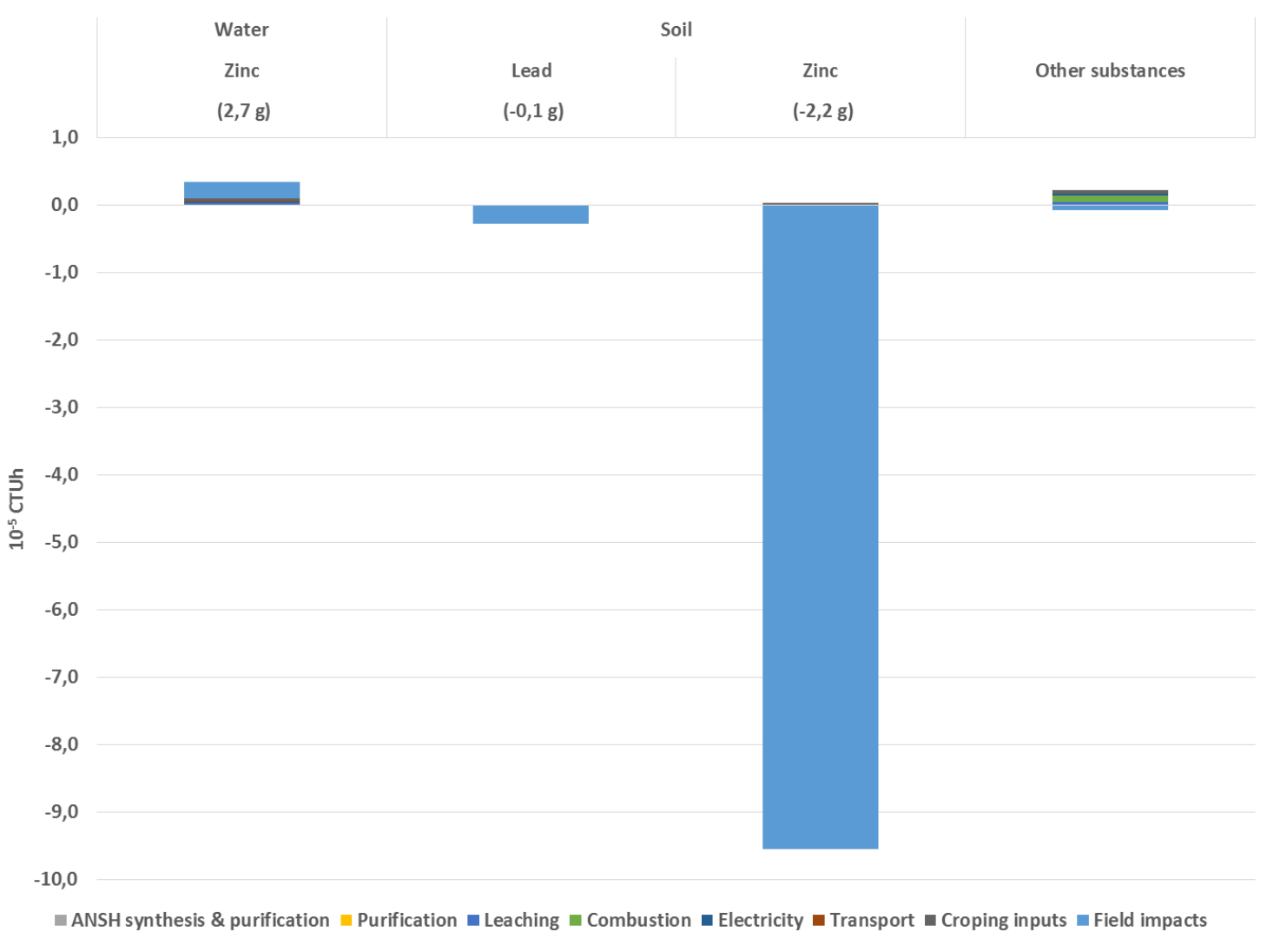

12

13 Supplementary Figure F8: Contribution of flows of substances to the impact category "Human toxicity. non cancer effects".

14 for 353g-ANSH, depending of their destination compartment and the emitted quantities

15

16 

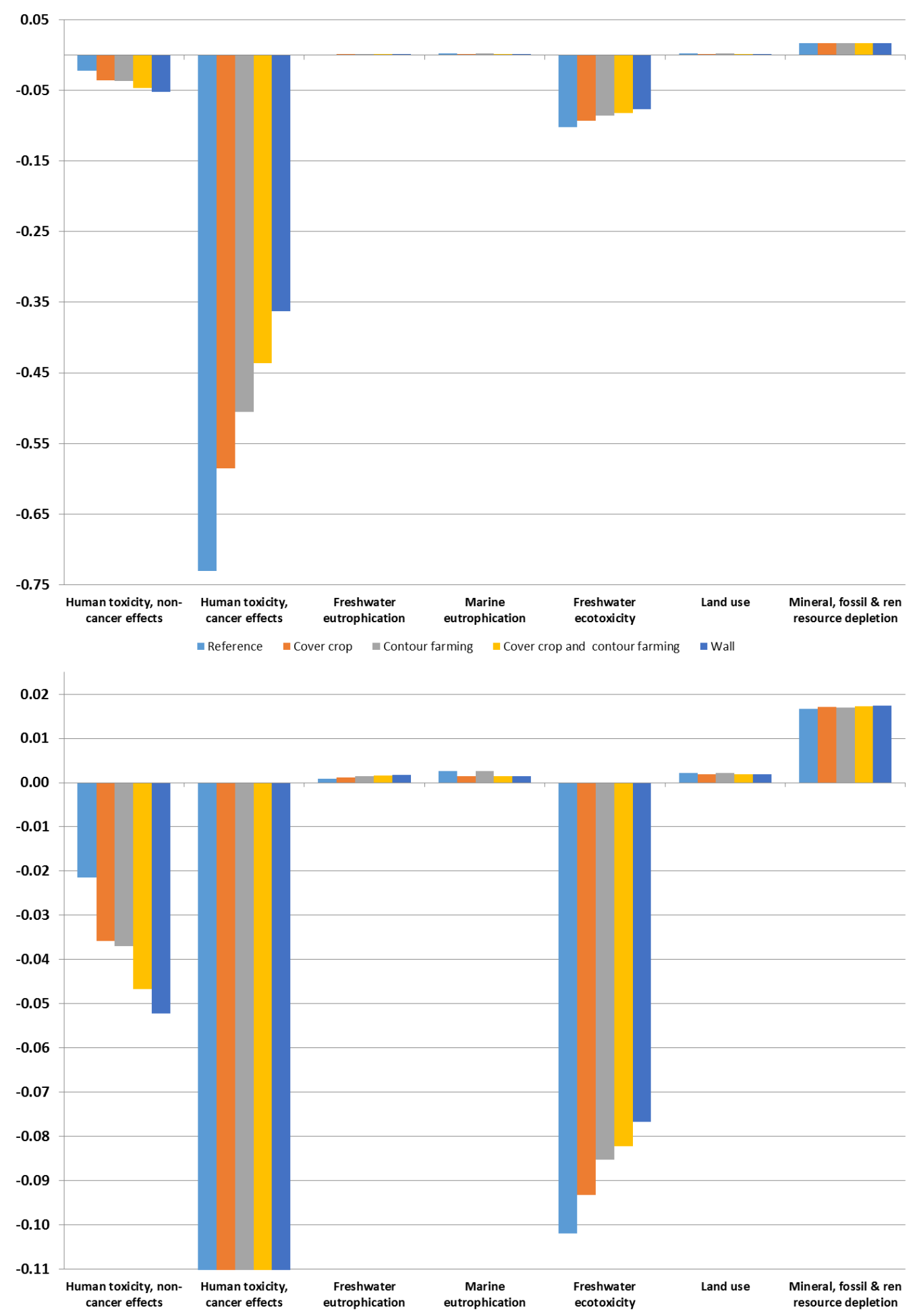

18 Supplementary Figure F9: Normalized life cycle impacts of $353 \mathrm{~g}$ ANSH produced in Albania, considering (1) change in erosion 19 compared to corn cultivation and (2) anti-erosion practices. Upper figure shows the global impacts; lower figure zooms on 20 the relatively lowest 